\title{
Effects of Resolution of Satellite-Based Rainfall Estimates on Hydrologic Modeling Skill at Different Scales
}

\author{
HUMBERTO VERGARA \\ Department of Civil Engineering and Environmental Science, and Advanced Radar Research Center, University \\ of Oklahoma, and National Severe Storms Laboratory, Norman, Oklahoma \\ YANG HONG \\ Department of Civil Engineering and Environmental Science, and Advanced Radar Research Center, University \\ of Oklahoma, Norman, Oklahoma \\ JONATHAN J. GOURLEY \\ National Severe Storms Laboratory, Norman, Oklahoma \\ Emmanouil N. Anagnostou, Viviana Maggioni, And Dimitrios Stampoulis \\ Department of Civil Engineering and Environmental Science, University of Connecticut, Storrs, Connecticut \\ PIERRE-EMMANUEL KIRSTETTER \\ Department of Civil Engineering and Environmental Science, and Advanced Radar Research Center, University \\ of Oklahoma, and National Severe Storms Laboratory, Norman, Oklahoma
}

(Manuscript received 27 July 2012, in final form 8 August 2013)

\begin{abstract}
Uncertainty due to resolution of current satellite-based rainfall products is believed to be an important source of error in applications of hydrologic modeling and forecasting systems. A method to account for the input's resolution and to accurately evaluate the hydrologic utility of satellite rainfall estimates is devised and analyzed herein. A radar-based Multisensor Precipitation Estimator (MPE) rainfall product (4 km, $1 \mathrm{~h})$ was utilized to assess the impact of resolution of precipitation products on the estimation of rainfall and subsequent simulation of streamflow on a cascade of basins ranging from approximately 500 to $5000 \mathrm{~km}^{2}$. MPE data were resampled to match the Tropical Rainfall Measuring Mission's (TRMM) 3B42RT satellite rainfall product resolution $(25 \mathrm{~km}, 3 \mathrm{~h})$ and compared with its native resolution data to estimate errors in rainfall fields. It was found that resolution degradation considerably modifies the spatial structure of rainfall fields. Additionally, a sensitivity analysis was designed to effectively isolate the error on hydrologic simulations due to rainfall resolution using a distributed hydrologic model. These analyses revealed that resolution degradation introduces a significant amount of error in rainfall fields, which propagated to the streamflow simulations as magnified bias and dampened aggregated error (RMSEs). Furthermore, the scale dependency of errors due to resolution degradation was found to intensify with increasing streamflow magnitudes. The hydrologic model was calibrated with satellite- and original-resolution MPE using a multiscale approach. The resulting simulations had virtually the same skill, suggesting that the effects of rainfall resolution can be accounted for during calibration of hydrologic models, which was further demonstrated with 3B42RT.
\end{abstract}

Corresponding author address: Yang Hong, National Weather Center ARRC, Suite 4610, 120 David L. Boren Blvd., Norman, OK 73072-7303.

E-mail: yanghong@ou.edu

\section{Introduction}

Satellite-based rainfall products have become an important resource for a broad variety of hydrological applications over the globe [e.g., flood forecasting, assessing 
water resources, and water management (Hong et al. 2006, 2007; Su et al. 2008; Pereira Filho et al. 2010; see also https://servirglobal.net/Global.aspx)], particularly for regions lacking in situ observational systems such as rain gauge networks. The success of current satellitebased rainfall estimates lies in their capability to resolve spatial patterns at scales largely unachievable on a global or continental scale by rain gauge networks. However, these estimates are accompanied by a host of uncertainties associated with the indirectness of distant radiance measurements and the platforms' limitations to capture the high spatiotemporal variability of the precipitation-related observations (McCollum et al. 2002; Sapiano and Arkin 2009; Gourley et al. 2010). Although progress has been made on characterizing the statistical properties of satellite retrieval error (e.g., Kidd et al. 2003; Hossain and Anagnostou 2006a,b; Dinku et al. 2010; Scheel et al. 2011) and their interaction with hydrologic processes and basin characteristics represented in hydrological models (e.g., Hossain and Lettenmaier 2006; Hong et al. 2007; Hossain and Huffman 2008; Nikolopoulos et al. 2010; Gourley et al. 2011; Maggioni et al. 2011), much work is still necessary for an optimal use of satellite-based precipitation in hydrology (Hossain and Katiyar 2008).

Since rainfall is the main forcing for hydrologic models in the generation of runoff, it is critical to understand how uncertainties associated to its estimation will propagate through the nonlinear dynamics embedded in these models. Arguably, the effects of error in rainfall volume on the simulation of hydrologic variables, such as streamflow, are rather intuitive. The spatial and temporal patterns inherent to rainfall, on the other hand, have been the interest of many hydrological studies (e.g., Ogden and Julien 1993; Obled et al. 1994; Koren et al. 1999; Arnaud et al. 2002; Smith et al. 2004; Segond et al. 2007; Younger et al. 2009). Moreover, the association of errors in volume and spatiotemporal representation of rainfall estimates with limitations in the precipitation sampling process has been extensively explored in relation to the effect on hydrologic applications (e.g., Kouwen and Garland 1989; Krajewski et al. 1991; Obled et al. 1994; Ogden and Julien 1994; Faurès et al. 1995; Dinku et al. 2002; Syed et al. 2003; Wang et al. 2009; Kirstetter et al. 2010; Mohamoud and Prieto 2012). This uncertainty stemming from sampling errors is an important drawback of the use of satellite-based rainfall estimates. Several studies have already pointed out that satellite rainfall products exhibit significant and complex uncertainty at high spatial and temporal resolutions (e.g., Kidd et al. 2003; Hossain and Anagnostou 2004; Nijssen and Lettenmaier 2004; Hong et al. 2006; Scheel et al. 2011). Thus, a natural consequence is that, although the error variability in coarse-resolution rainfall products may be smoothed out, their resolution may not be acceptable at the scales required for some hydrologic modeling applications (e.g., flash flood forecasting). It has been shown that the spatial scale of the application can impact the propagation of this uncertainty in flood modeling (e.g., Nikolopoulos et al. 2010). Therefore, understanding how satellite rainfall retrieval uncertainty manifests in hydrologic prediction requires studying the effects of basin-scale and spatiotemporal resolution on the rainfall error. Accounting for the error due to rainfall input resolution in an explicit manner has proven to be fundamental for evaluating satellite rainfall inputs' hydrologic potential (Gourley et al. 2011).

In this work, we expand the work of Gourley et al. (2011) by presenting a methodology to explicitly account for the effects of rainfall estimates' resolution in hydrologic modeling, the basis of which is a parameter estimation procedure that considers basin scale. As the effect of satellite rainfall resolution on hydrologic simulation is a significant one, this study promotes its consideration when evaluating satellite rainfall inputs in a hydrologic context. A systematic analysis of the effects of current satellite rainfall products' resolutions on the hydrologic modeling is performed for a cascade of basins of small to medium size $\left(500-5000 \mathrm{~km}^{2}\right)$. It must be recognized that the errors in the hydrologic simulation result from a complex interaction between the uncertainty in the input (i.e., rainfall), the model structure and approximations, the estimation of model parameters and other variables (e.g., potential evapotranspiration), and observations (e.g., gauged streamflow). In the present study, the effect of satellite rainfall products' resolution was effectively isolated from other sources of uncertainty through a synthetic experiment with a hydrologic model used in operational settings. Studying the errors in hydrologic simulation due to rainfall resolution alone can serve the purpose of indicating the appropriateness of satellite product resolutions regarding basin-scale and streamflow magnitude (e.g., water resources management versus high-impact flooding events). Likewise, it can help understand limitations and indicate possible improvements in the next generation of satellite rainfall products from the Global Precipitation Measurement (GPM) mission. In a similar work, Nijssen and Lettenmaier (2004) explored the impact of sampling error on the precipitation volume and its subsequent effect on the hydrologic modeling of a cascade of basins using gridded gauge-based estimates and a macroscale hydrologic model. In the present study, the impact of satellite product resolution on the spatial variability and structure of rainfall estimates is additionally analyzed.

The key aspects that this work seeks to explore can be put into context as follows: given that satellite precipitation 
products are available in regions where other sources of rainfall observations are sparse or nonexistent, it is critical to establish their usefulness for hydrologic applications. A common approach in determining the hydrologic utility of satellite rainfall consists of calibrating a hydrologic model to the product subject to evaluation (see, e.g., Yilmaz et al. 2005; Artan et al. 2007; Yong et al. 2010). While this method can show the performance of the satellite product within the particular modeling setup, the utility of satellite rainfall is obscured by the calibration strategy and the model's ability to accommodate the observational data (e.g., streamflow) during estimation of its parameters. An alternative method consists of calibration of the hydrologic model to what is considered the "true" rainfall, followed by an evaluation of the hydrologic simulation's performance forced by the satellite product (see, e.g., Su et al. 2008; Li et al. 2009; Gourley et al. 2011). In this case, the differences in hydrologic skill stem from inherent abilities to estimate the rainfall of each product and their corresponding spatiotemporal resolutions. Therefore, eliminating the latter conditioning factor in the evaluation process is required to accurately reveal the hydrologic utility of satellite precipitation products. In other words, an accurate evaluation of the hydrologic utility of satellite precipitation products as a function of basin-scale and streamflow magnitude is herein defined as one that can account for the effects of the precipitation product's resolution. To address this issue, this study aims to establish how important the effects of rainfall estimates' resolution are for hydrologic applications, whether they can be accounted for or not, and whether this can help to determine the hydrologic utility of satellite rainfall estimation. Several scientific questions are in order:

1) What is the impact of sampling error on rainfall fields in terms of magnitude, spatial variability, and spatial structure?

2) How are the corresponding hydrologic simulations affected?

3) Given the nonlinear nature of hydrologic processes, are these effects magnified or dampened, and does the size of the watershed play an important role?

4) Since model calibration is usually employed to compensate for errors in the input data along with other sources of uncertainty in the modeling system, can the effects analyzed in 2) and 3) be effectively mitigated through adjustment of model parameters?

5) Most importantly, can model calibration serve as a method to explicitly account for input's resolution and accurately reveal the utility of satellite rainfall products?

To answer the aforementioned questions, a highresolution, radar-based rainfall product was resampled to match the resolution of the 3B42RT product from the Tropical Rainfall Measurement Mission (TRMM; Huffman et al. 2007). Additionally, the dependency of the product's resolution effect on rainfall or streamflow relative magnitudes (i.e., mean values versus extreme high values) is studied. Finally, we present a strategy through the estimation of the hydrologic model parameters to account for the impact of resolution in the evaluation of satellite rainfall products. The method is put to the test using TRMM's 3B42RT estimates to force the hydrologic simulations from the resulting model setup. The remainder of the paper is organized as follows. Section 2 presents the study area and the data employed for the experiments. In section 3, the first three questions are addressed through the synthetic experiment for isolating the effect of rainfall product's resolution. Section 4 reports the analysis of the last two questions using a general-purpose optimization algorithm, and section 5 summarizes the work and outlines the conclusions.

\section{Study area and data}

This study region focuses on the catchment of the U.S. Geological Survey (USGS) station located at Tarboro (stream gauge 02083500), a subcatchment of the TarPamlico River basin located in coastal North Carolina (Fig. 1). The basin is periodically affected by heavy rainfall from tropical storms and hurricanes, at which times major flood events occur. Because of these coastal impacts, the basin has been a subject of research for the National Oceanic and Atmospheric Administration's (NOAA) Coastal and Inland Flooding Observation and Warning (CI-FLOW) project (Van Cooten et al. 2011). Tarboro's catchment consists of the upper Tar River and Fishing Creek subbasins for a total drainage area of $5709 \mathrm{~km}^{2}$. Located on the coastal plain, the elevation for this catchment ranges from 2.8 to $225.7 \mathrm{~m}$ MSL. The Tar is a perennial river with a minimum recorded daily flow of $0.79 \mathrm{~m}^{3} \mathrm{~s}^{-1}$, a mean of $62 \mathrm{~m}^{3} \mathrm{~s}^{-1}$, and a maximum of $1,996 \mathrm{~m}^{3} \mathrm{~s}^{-1}$ at Tarboro. Subhourly streamflow observations are available at eight interior locations of Tarboro spanning from October 1985 to present at the USGS Instantaneous Data Archive (IDA; USGS 2011). Five of the measurement sites located on the main stem were selected to derive hourly streamflow observations for the experiments conducted herein. The distribution of the sites forms a cascade of subcatchments ranging from 529 to $5709 \mathrm{~km}^{2}$.

The quantitative precipitation estimation (QPE) product used herein as ground reference was the U.S. National Weather Service (NWS) Multisensor Precipitation Estimation (MPE) product. MPE data are derived employing 


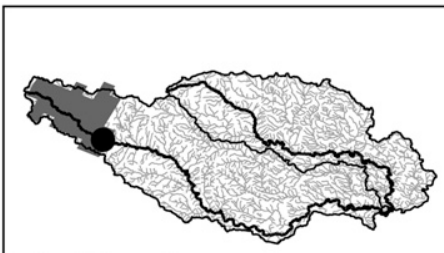

B1: 529 sq-km
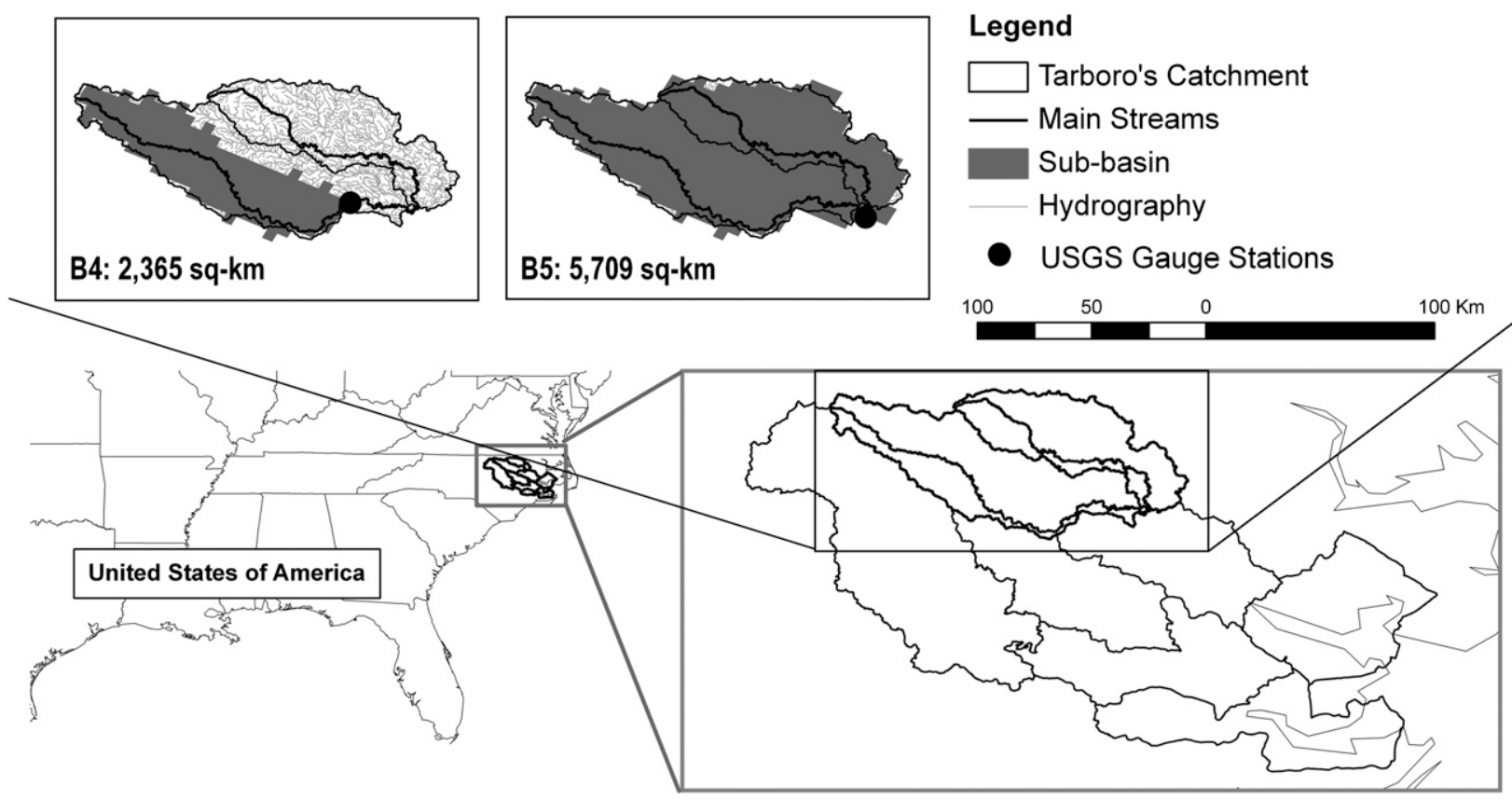

FIG. 1. Study area showing the selected subbasins (B1-B5) and associated gauge locations within the catchment of Tarboro's USGS streamflow gauge station in the Tar River basin, North Carolina. The hydrography of the basin is presented highlighting main streams.

a blend of automated and interactive procedures to combine information from satellite, radar, and rain gauges (Briedenbach and Bradberry 2001; Fulton 2002; Seo et al. 2010). Hourly MPE data are available for the Southeast River Forecast Center (SERFC) region at the Hydrologic Rainfall Analysis Project (HRAP; Schaake 1989) resolution from 2002 to present. The size of an HRAP grid cell is approximately $4 \times 4 \mathrm{~km}^{2}$.

The satellite product used in this work was the near-realtime infrared and microwave merged TRMM precipitation product 3B42RT, version 6 . The 3B42RT estimates are available at $0.25^{\circ}(\sim 25 \mathrm{~km})$ and 3-hourly time intervals (Huffman et al. 2007). A total of $8 \mathrm{yr}$ of data (2002-09) overlapping MPE and 3B42RT archives was employed and analyzed in this study. The 3B42RT estimates were resampled to MPE's HRAP resolution for comparison and subsequent use in the hydrologic model. Figure 2 presents an evaluation of 3B42RT performance as compared to MPE for the period of data. Mean annual totals (Figs. 2a,b) are shown along with spatially distributed relative bias [Eq. (1); Fig. 2c] and relative RMSE [Eq. (2); Fig. 2d]:

$$
\operatorname{bias}(\%)=\frac{\sum_{i=1}^{N}\left(X_{i}^{\mathrm{sim}}-X_{i}^{\mathrm{ref}}\right)}{\sum_{i=1}^{N} X_{i}^{\mathrm{ref}}} \times 100
$$

and

$$
\operatorname{RMSE}(\%)=\frac{\sqrt{\frac{\sum_{i=1}^{N}\left(X_{i}^{\mathrm{sim}}-X_{i}^{\mathrm{ref}}\right)^{2}}{N}}}{\bar{X}^{\mathrm{ref}}} \times 100,
$$

where $X_{i}^{\text {sim }}$ is the variable under evaluation (i.e., 3B42RT) value at time $i, X_{i}^{\text {ref }}$ is the reference value (i.e., MPE) at time $i$, and $\bar{X}^{\text {ref }}$ is the average reference value over the simulation interval. The clear southeast-northwest 


\section{a) MPE}

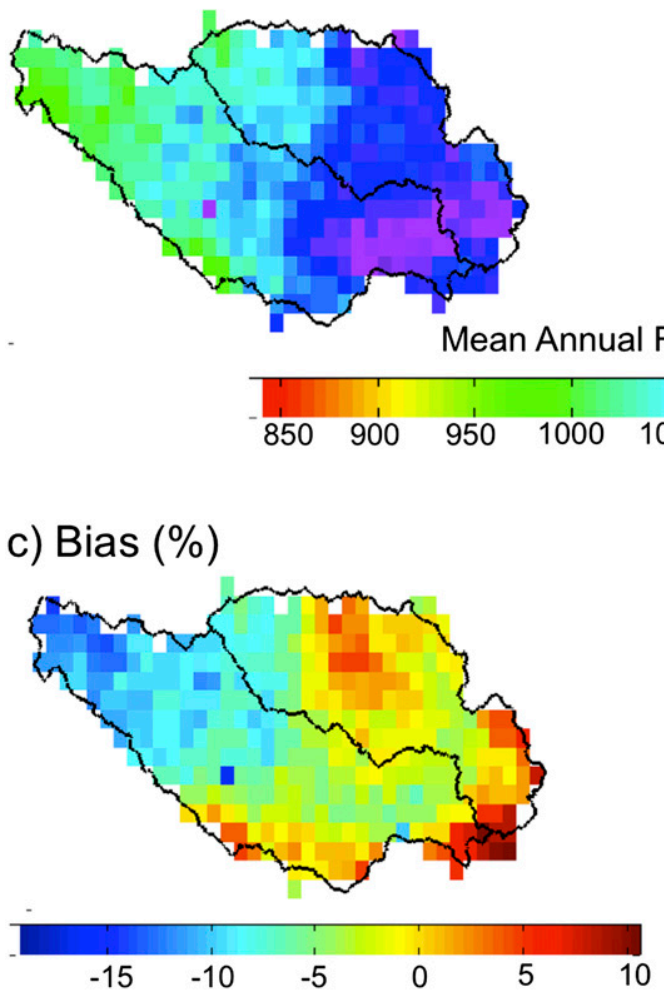

b) 3B42RT

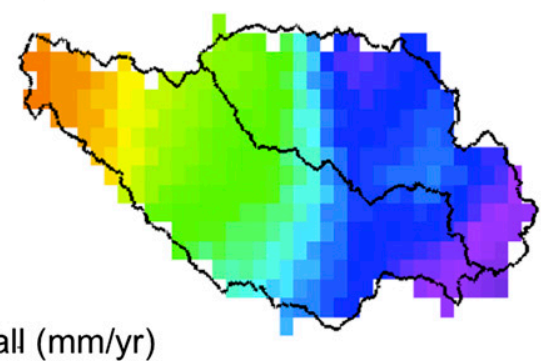

$1050 \quad 1100 \quad 1150 \quad 1200 \quad 1250$

FIG. 2. Performance evaluation of 3B42RT rainfall estimates for the 2002-09 period at 4-km and 1-h resolutions: the spatial distribution of mean annual rainfall from (a) MPE and (b) 3B42RT and the spatial distribution of the hourly-based mean relative (c) bias and (d) percent RMSE.

precipitation gradient over the basin shown in Fig. 2a is generally well captured by 3B42RT (Fig. 2b). However, 3B42RT significantly underestimates at the upper part of the basin, where the lowest amounts of rainfall occur. This can also be seen in Fig. 2c, where values of negative bias range from about $-5 \%$ to $-15 \%$ for the upper part and there are areas of overestimation on the middle and lower parts of the basin. The relative RMSE is significantly high, with values ranging from about $550 \%$ to $750 \%$, where the highest values generally occur at the lower part of the basin. These errors result from the combination of discrepancies between 3B42RT and MPE in terms of both spatiotemporal resolution and retrieval capabilities. The following section presents an analysis to describe the contribution of the input's resolution to these errors and its impact on hydrologic predictions.

\section{Isolating uncertainty due to rainfall product resolution}

This work concentrated on the error contributed by the rainfall products' spatiotemporal resolution. Specifically, this is the resolution error associated with current d) RMSE (\%)

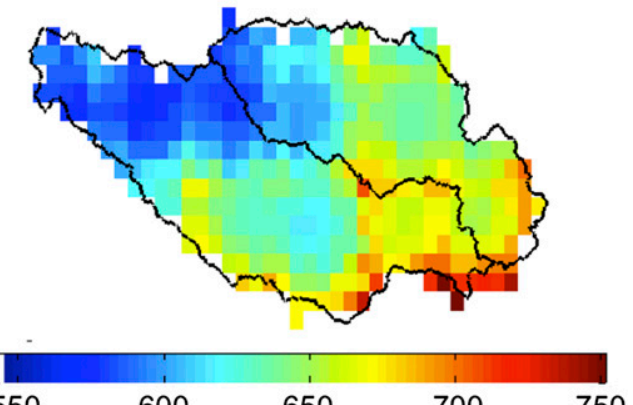

satellite-based QPEs as compared to ground reference products, which are generally considered as the ground truth. To create a scenario where all other sources of uncertainty can be virtually neglected, the reference highresolution QPE product (i.e., MPE at $4 \mathrm{~km}$, hourly) was resampled to the coarser resolution of TRMM satellite products (i.e., $25 \mathrm{~km}, 3$ hourly). The resampling method consisted of a simple computation of the unconditional mean of all the 4-km pixels within a given $25-\mathrm{km}$ pixel for the spatial aggregation [Eq. (3)] and a centered weighted average computation involving the four closest time steps for the temporal aggregation [Eq. (4)]:

$$
R_{i, j}^{25 \mathrm{~km}}=\frac{\sum_{k=1}^{n}\left(\sum_{l=1}^{m} R_{k, l}^{4 \mathrm{~km}}\right)}{n \times m}
$$

and

$$
R_{i, j, t}^{25 \mathrm{~km}}=w_{1}\left(R_{i, j, t-1}^{25 \mathrm{~km}}+R_{i, j, t+1}^{25 \mathrm{~km}}\right)+w_{2}\left(R_{i, j, t-2}^{25 \mathrm{~km}}+R_{i, j, t+2}^{25 \mathrm{~km}}\right),
$$

where $R_{i, j}^{25 \mathrm{~km}}$ is the rain rate at the resampled $i$ th, $j$ th $25-\mathrm{km}$ grid point resulting from the average of the $4-\mathrm{km}$ 
grid points in the region delimited by the $n \times m$ (rows, columns) box; $w_{1}$ and $w_{2}$ are weights for the temporal averaging of rain rates in the interval from $t-2$ to $t+2$ with values 0.15 and 0.35 , respectively; and $R_{i, j, t}^{25 \mathrm{~km}}$ is the rain rate degraded in both spatial and temporal resolution at time $t$. In this section, results and their corresponding analysis are based on comparisons between the high- and coarse-resolution versions of MPE, referred to hereafter as HR-MPE and CR-MPE, respectively.

\section{a. Effects on rainfall estimates}

The first step in this analysis was an examination of the overall impact of resolution on rainfall estimates. Since this particular aspect has been well studied and documented in previous studies (e.g., Obled et al. 1994; Ogden and Julien 1994), some of the results described herein are not included in the main document but can be found in appendix A and B. The difference in resolution introduces considerably large errors in the estimates with values of RMSE of about $150 \%-350 \%$ for annual grids and about $650 \%-750 \%$ for the entire period of data (Fig. A1). Although the values of bias are in general not significant, there is considerable variability in some of the years, with biases ranging from more than $20 \%$ overestimation to about $10 \%$ underestimation. Moreover, a clear interannual variability was observed in terms of these error signatures. This is most probably related to the rainfall regime and characteristics of individual storms of each year. Years dominated by smallscale convection are more likely to be associated with relatively high RMSE because of a smoothing effect when aggregating up to the coarser $25-\mathrm{km}$ pixel scale. This issue was explored through an analysis of the effect of QPE's resolution degradation on the spatial structure of rainfall for 100 representative storm events from the entire period of record. A relatively simple method based on variograms (Journel and Huijbregts 1978) proposed by Lebel et al. (1987) and followed by subsequent studies (e.g., Berne et al. 2004; Kirstetter et al. 2010; Kirstetter et al. 2012) was used herein to characterize the differences in spatial structure between HRMPE and CR-MPE. Assuming the rainfall field to be a realization of a random function, the variogram represents the spatial correlation of the rain field and is defined as half the expectation of the quadratic increments between estimates of rainfall as a function of interdistance between the points of estimation. In the multirealization case (e.g., rainfall fields in successive hourly accumulations for a given event), it is convenient to take into account information from all the realizations to infer a single and more robust empirical variogram, assuming the fields to have similar statistical characteristics except for a constant factor. Times with zero rainfall are not considered in computing the variogram. In this study, we used the approach proposed by Lebel et al. (1987) based on a normalized variogram established by scaling each squared increment by the field variance. A standard model is fitted to the empirical mean variogram. The exponential model of the following general form was found suitable:

$$
\gamma(h)=C_{0}+\left(C-C_{0}\right)\left[1-e^{(-h) / d}\right],
$$

where $\gamma$ is the variogram function ranging from 0 to $1 ; h$ is the interdistance in kilometers; and $C_{0}$ and $d$ are the variogram model parameters called the nugget (dimensionless) and the range (kilometers), respectively. The nugget is the value of the variogram at the origin, which can be related either to variability poorly resolved by the product or to measurement error (Kirstetter et al. 2010). The sill, $C$, is the value at which the variogram asymptotically approaches when $h$ tends to infinity. In the case of normalized variograms, the sum of the nugget and sill equals 1.0. The range is the interdistance at which the variogram reaches the sill and is defined as the mean decorrelation distance of the measurements, which can be used as an indicator of the characteristic spatial scale of a storm: large systems such as tropical storms and hurricanes can be characterized by large range values, while small range values can be associated to small-scale convection. Because this analysis requires a large enough spatial domain to correctly characterize the spatial structure of rainfall, it is only applied at the largest scale (i.e., B5 basin). The nugget and range were used herein to describe the spatial structure of the selected storms.

Figure 3 shows scatterplots of selected variogram parameters and their association to the effect of resolution degradation for the 100 events. Figures $3 a$ and $3 b$ directly demonstrate the modification of rainfall spatial structure features (i.e., range and nugget, respectively). The effect is clear and directly proportional to both the nuggets and the ranges of the storms as observed by the high-resolution product. The trend of the nugget indicates that for events with values less than about 0.1 , the effect of resolution is higher. Furthermore, Figs. $3 \mathrm{c}$ and $3 \mathrm{~d}$ present the association of the modification of these spatialstructure characteristics of rainfall to error due to resolution degradation. For the case of the variogram range, there is a direct relationship with the basin-averaged relative RMSE. This indicates that introduction of spurious spatial correlation due to smoothing effects promotes the introduction of aggregated error, which increases with decreasing storm scale, as shown in Fig. 3a. The inverse relationship between nugget ratio and RMSE displayed in Fig. 3d clearly shows that increasing inabilities to resolve variability at small scales results in error as 

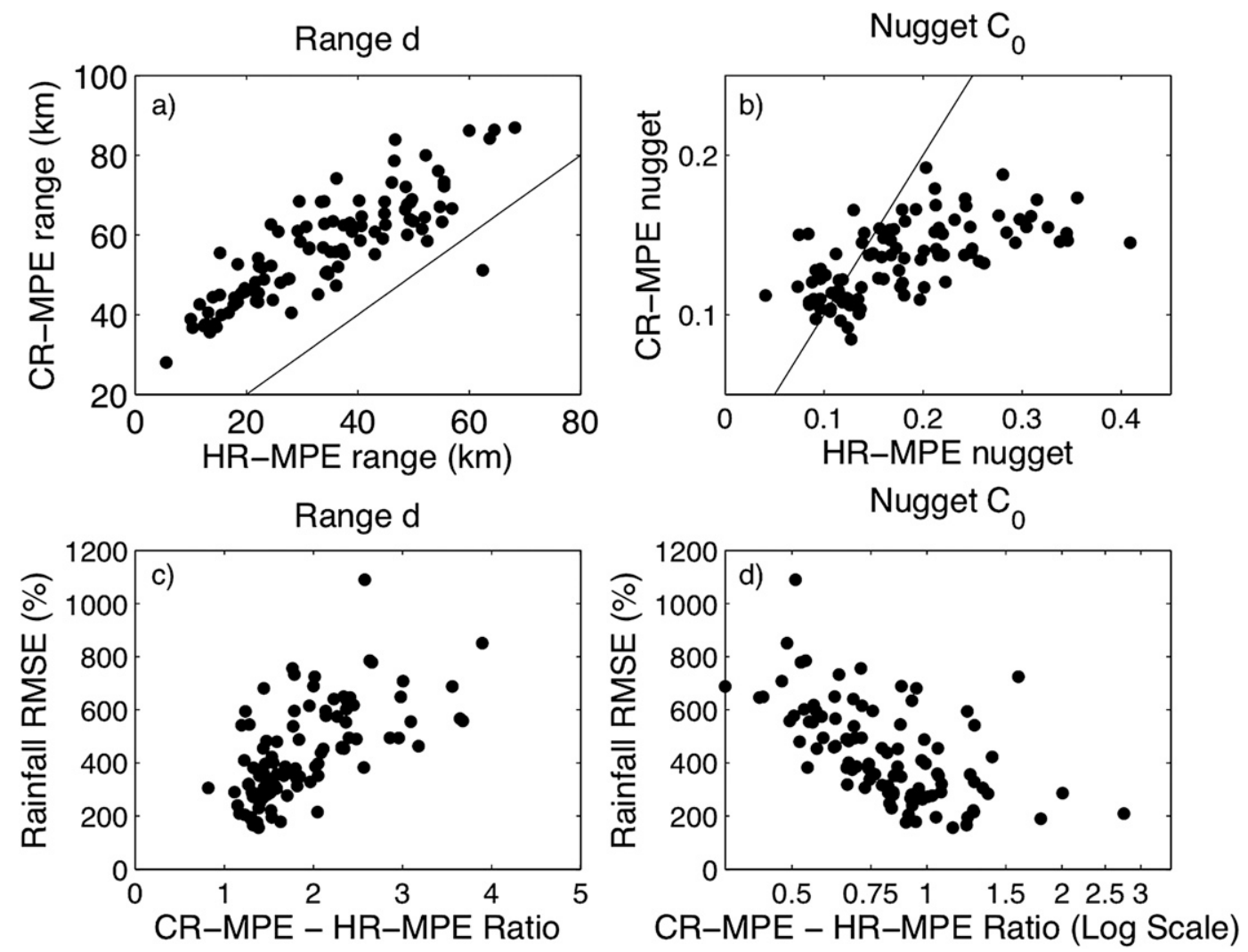

FIG. 3. Effect of resolution degradation on the spatial structure of rainfall for 100 events: (a) HR-MPE range vs CR-MPE range (solid line represents 1:1 relation), (b) HR-MPE nugget vs CR-MPE nugget (solid line represents 1:1 relation), (c) basin-averaged relative RMSE (\%) as a function of the ratio of ranges, and (d) basin-averaged relative RMSE (\%) as a function of the ratio of nuggets (log scale).

well. These results illustrate that coarser-resolution QPE results in error as quantified through an analysis of the spatial characteristics of rainfall fields.

\section{b. Propagation into hydrologic modeling}

\section{1) HYDROLOGIC MODEL}

The NWS Hydrology Laboratory Research Distributed Hydrologic Model (HL-RDHM), whose precursor was the NWS Hydrology Laboratory Research Modeling System (HL-RMS; Koren et al. 2004), was employed here to evaluate the effect of rainfall forcing resolution on the simulation of streamflow. The modeling system consists of the Sacramento Soil Moisture Accounting Model (SAC-SMA; Burnash et al. 1973) for the water balance/runoff generation and a kinematic wave model for the hillslope and channel routing. These two components are applied to each cell in a rectangular grid at the HRAP resolution in a polar stereographic projection, which directly corresponds to the MPE product.

The SAC-SMA is a conceptual rainfall-runoff (CRR) watershed model widely used within the NWS River
Forecast System (Sorooshian et al. 1993; Boyle et al. 2000; Koren et al. 2004). The model structure and other details are well described in Koren et al. (2000, 2003, 2004) and Yilmaz et al. (2008), so we focus on the presentation of the model parameters and their estimation here. The model simulates runoff generation using 17 conceptual parameters (Table B1). Koren et al. (2000) developed an approach to estimate values for 11 of the SAC-SMA parameters based on the State Soil Geographic (STATSGO; Soil Survey Staff 1994, 1996) soil data. The remaining six parameters use lumped values established by the NWS from previous experience on different basins (Pokhrel et al. 2008; Yilmaz et al. 2008). Another input in SAC-SMA (i.e., in addition to gridded precipitation data) is potential evaporation (PE) data. Twelve climatological mean monthly potential evaporation grids, available at the HRAP resolution for the continental United States, were used in this study. HL-RDHM's user manual (NWS 2008) describes how these grids were derived.

The flow-routing component in HL-RDHM is divided into hillslope routing (overland flow) and channel routing. Values for the parameters controlling overland flow 

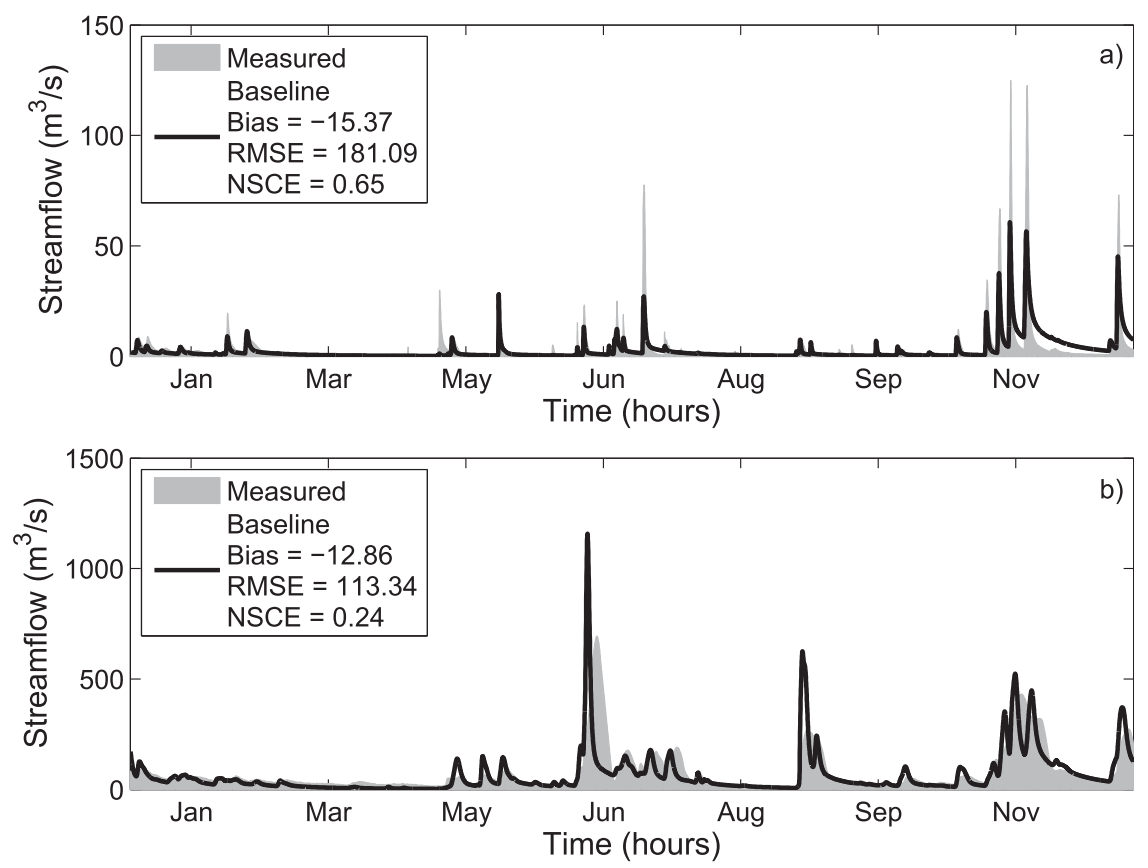

FIG. 4. Simulation of streamflow during 2006 with the baseline model at (a) smallest-scale basin (B1) and (b) largest-scale basin (B5). Measures of performance for the simulation are presented in the legend.

were derived from a high-resolution digital elevation model (DEM), land use data, and results reported from initial tests on the model (NWS 2008). The channel routing parameters $q_{m}$ and $q_{0}$ were specified using a discharge to cross-sectional area relationship through a rating curve method (Koren et al. 2004):

$$
Q=q_{0} A^{q_{m}},
$$

where $q_{m}$ and $q_{0}$ were determined using measurements of $Q$ and $A$ data at eight stations within Tarboro's catchment (USGS stations 02081500, 02081747, 02082506, 02082585，02082770，02082950，02083000，02083500). Using HL-RDHM's built-in tools, spatially distributed grids for the two channel-routing parameters were created.

The aforementioned setup yielded a model referred to hereafter as the baseline model. Koren et al. (2003) report that the a priori estimates give reasonable initial values for SAC-SMA parameters and reduce uncertainties in their ranges. Figure 4 presents a 1 -yr hourly simulation of streamflow with the baseline model forced by HR-MPE at the smallest and largest basins (Figs. 4a,b) to evaluate the validity of the setup. The simulation was compared to the observed streamflow, and metrics of goodness of fit, commonly employed to assess hydrologic model performance, were computed to illustrate the model's skill in describing the observed overall response of the basin to rainfall. Visual inspection of the hydrographs reveals that even with no calibration involved in the estimation of model parameters, the skill of the simulation in capturing the direct response to rainfall (i.e., occurrence of peak flows) as well as the baseflow in both basins is high. The values of the error metrics (i.e., relative bias and relative RMSE) are only slightly higher at the smallest basin because of underestimation of the magnitude of some of the peaks. The value of the Nash-Sutcliffe coefficient of efficiency (NSCE), a measure commonly used in hydrology to summarize simulation skill, is relatively high at the smallest basin $(\mathrm{NSCE}=0.65)$ and relatively low at the largest basin (NSCE $=0.23$ ). The lower value of NSCE for the simulation at the largest scale is primarily a result of low covariance between observed and simulated streamflow time series due to timing offsets. This timing issue is caused by limitations in the estimation of the routing parameters [i.e., $q_{m}$ and $q_{0}$ in Eq. (6)], which have a larger impact on medium-to-large basins given that the lag in the response to rainfall is directly correlated to catchment size. Dramatic improvement in simulation timing can be achieved by only adjusting the two routing parameters (NSCE above 0.8 ; not shown here).

\section{2) SENSITIVITY OF STREAMFLOW SIMULATIONS TO RAINFALL RESOLUTION ALONE}

We use the baseline model to isolate error in the hydrologic simulations associated to rainfall forcing's 
a) Bias (\%)

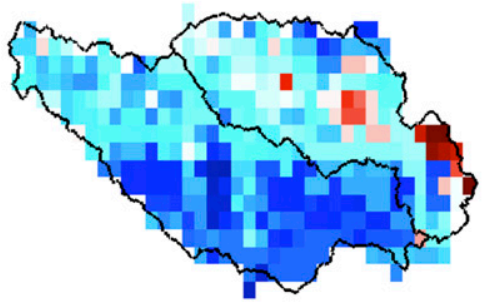

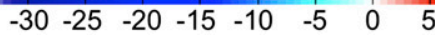

b) RMSE (\%)

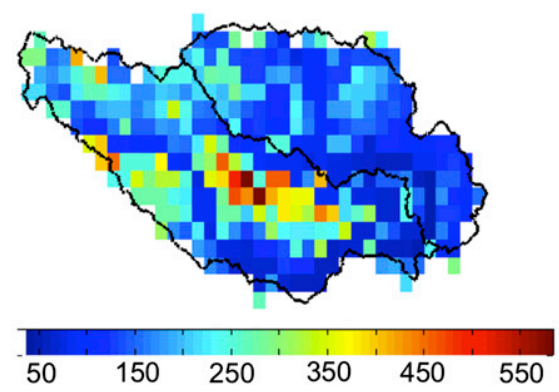

c) NSCE

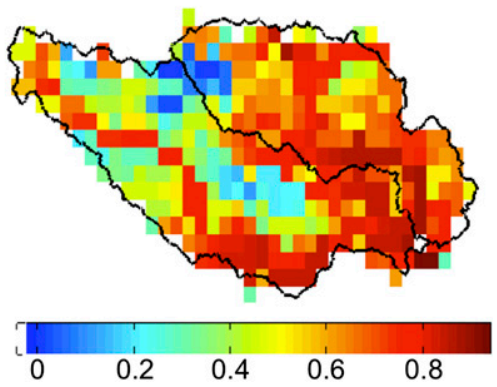

FIG. 5. Grid-based comparison of streamflow forced by CR-MPE and HR-MPE for the synthetic experiment: (a) relative bias, (b) relative RMSE, and (c) NSCE.

resolution alone, because the parameters are based on soil and land use data that are independent from the rainfall algorithms. A calibrated model, on the other hand, will be conditioned on the input and reference data (e.g., measured streamflow). To neglect the other sources of uncertainty, including model structure and approximations, the simulation forced by HR-MPE was used as the reference to evaluate precipitation resolution errors in the hydrologic simulation forced by CRMPE. The use of hydrologic simulations as reference also enables us to compare simulations at each grid point across scales. The basic assumption of this synthetic experiment is that the hydrologic model represents basin response to rainfall and that the HR-MPE dataset represents the actual surface rainfall; loss in skill in the hydrologic simulations using the CR-MPE forcing is from precipitation estimate's resolution alone. The analysis presented herein was fixed to the hourly modeling temporal scale since, first, this is the reference resolution of HR-MPE and, second, it is the scale at which resampled rain estimates exhibited the greatest uncertainty (Fig. A2).

Figure 5 presents a grid-based comparison of simulated streamflow forced by CR-MPE and the synthetic reference for the 2002-09 period. Overall, we notice that streamflow is underestimated across the catchment, although there is some overestimation in Fishing Creek's subcatchment (upper portion of Tarboro's catchment). Additionally, the propagation of aggregated errors from the CR-MPE rainfall to streamflow presents a clear pattern. The relatively low RMSE and high NSCE values are collocated in large-scale streams and rivers. Furthermore, it can be seen how the model performance degrades moving in the upstream direction toward headwaters. This is consistent with results from previous studies in relation to the inverse association between resolution impact and drainage area (e.g., Nijssen and Lettenmaier 2004). A more detailed investigation on basin-scale dependence follows.

A summary of the magnitude of errors in rainfall and streamflow for the 2002-09 period and the five basins considered in this work are presented in Table 1. The relative RMSE and NSCE of streamflow generally improve with increasing basin scale. The relative bias, on the other hand, does not display a clear trend with basin scale. The values of bias seem to worsen from B1 to B4, but it improves when going to B5. This behavior is consistent with the mean relative bias of rainfall and the gradient of mean rainfall over the basin shown in Fig. 2a. Moreover, it can be seen that the global bias in streamflow simulations stemming from QPE resolution difference is relatively low, while the RMSE is considerably high. Figure 6 shows the same metrics in Fig. 5, but expressed as ratios to corresponding rainfall error and plotted as a function of basin catchment area for different streamflow thresholds. These results illustrate the error propagation and possible dampening or magnification of resolution-related errors by the nonlinear transformation of rainfall to runoff in integrated basins. Nikolopoulos et al. (2010) examined rainfall error propagation in a complex terrain basin in northeastern Italy and found that it depended on the metric of reference. For example, the relative error in rainfall translated to a lower relative error in runoff volume, while the same rainfall error resulted in a magnified relative error in peak discharge (in most ensembles). In our case, the global bias in rainfall significantly magnified into higher global bias in streamflow. Moreover, this magnification increased with decreasing basin scale with an abrupt jump from a factor of about 6.0 to a factor of a little over 20.0 when going from B2 to B1 for the case that considers all flow values [i.e., the thick black line, $Q(100 \%)]$. On the other hand, the aggregated errors in rainfall were greatly dampened in the streamflow simulations. Furthermore, the reduction in error directly correlated with basin scale with a factor close to 6.0 ( $Q$ to $R$ RMSE ratio of $\sim 0.17$ ) for $\mathrm{B} 1$ and over 20.0 ( $Q$ to $R$ RMSE ratio of $\sim 0.048$ ) for B5 for the case that considers all flow values.

Figure 6 also presents metric values for different streamflow exceedance thresholds. It can be seen that 
TABLE 1. Summary of overall error metrics for basin-averaged rainfall and streamflow at basin outlet for the 2002-09 period. Values are presented for all subbasins.

\begin{tabular}{lcccccc}
\hline \hline & \multicolumn{2}{c}{ Rainfall error } & & \multicolumn{3}{c}{ Streamflow error } \\
\cline { 2 - 3 } \cline { 6 - 7 } Subbasin & $\begin{array}{c}\text { Bias } \\
(\%)\end{array}$ & $\begin{array}{c}\text { RMSE } \\
(\%)\end{array}$ & & $\begin{array}{c}\text { Bias } \\
(\%)\end{array}$ & $\begin{array}{c}\text { RMSE } \\
(\%)\end{array}$ & NSCE \\
\hline $\mathrm{B} 1,529 \mathrm{~km}^{2}$ & -0.25 & 674 & & -5.33 & 112 & 0.72 \\
$\mathrm{~B} 2,1089 \mathrm{~km}^{2}$ & -1.10 & 675 & & -6.71 & 77.7 & 0.79 \\
$\mathrm{~B} 3,1982 \mathrm{~km}^{2}$ & -2.67 & 675 & & -11.21 & 57.1 & 0.84 \\
$\mathrm{~B} 4,2365 \mathrm{~km}^{2}$ & -2.95 & 682 & & -12.03 & 68.3 & 0.80 \\
$\mathrm{~B} 5,5709 \mathrm{~km}^{2}$ & -1.96 & 691 & & -8.17 & 33.1 & 0.94 \\
\hline
\end{tabular}

the impact of QPE resolution difference increases nonlinearly as the probability of occurrence of streamflow decreases, which negatively affects the skill of the modeling system to simulate extreme flooding events. The difference in relative RMSE (inferred from the differences in $Q$ to $R$ ratio) and NSCE between $Q(100 \%)$ and $Q(10 \%)$ is greatest at the smallest basin scales. Also, the QPE resolution impact appears to be greatest for the highest flow thresholds and at the smallest basin scales, which have implications on hydrologic applications such as flash flood modeling. Furthermore, the dampening of random error decreases with increasing streamflow threshold. On the other hand, the global bias and its magnification are not significantly affected. A reduction on the magnification, however, can be noticed when considering the highest flow thresholds [i.e., $Q(10 \%)$ ].

Last, the effect of resolution is assessed at the scale of specific events, which allows for a more detailed examination of the rainfall error propagation to streamflow simulations. Figure 7 presents a summary of the error features of rainfall estimates (i.e., magnitude, spatial variability, and spatial structure) introduced by resolution degradation and their propagation to hydrologic simulations. The sample of 100 events used in the analysis in section $3 \mathrm{a}$ was employed for this purpose. The error magnitude was defined as the basin-averaged mean differences between CR-MPE and HR-MPE over the event interval. Similarly, the error spatial variability was defined as the mean basin standard deviation of differences between CR-MPE and HR-MPE over the event interval. Finally, the error spatial structure was defined computing the variogram of rainfall differences between CR-MPE and HR-MPE for each event and comparing their ranges to those of HR-MPE's variograms. These rainfall error features were contrasted to the corresponding streamflow error across the basin ( $y$ axis for error magnitude and error variability panels) and at the basin outlet described by the relative bias (top panels) and relative RMSE (bottom panels).

In terms of error magnitude (Fig. 7, left), there is a definitive connection between basin-averaged rainfall and streamflow errors. Moreover, the relative bias in streamflow simulations at the outlet is clearly associated to the aforementioned connection of error magnitudes. The relative RMSE displays a similar association with the basin-averaged differences. Furthermore, it can be observed that most of events with relatively low RMSE (i.e., below $\sim 20 \%$, blue-colored events) are associated to events with positive bias (around 10\%-20\%). This indicates that the effect of resolution for these particular events is mostly reflected in relative bias. In terms of error spatial variability (Fig. 7, middle), rainfall differences also correlate to streamflow differences across the basin, although not as strongly as the error magnitude does. However, there is not a clear association with

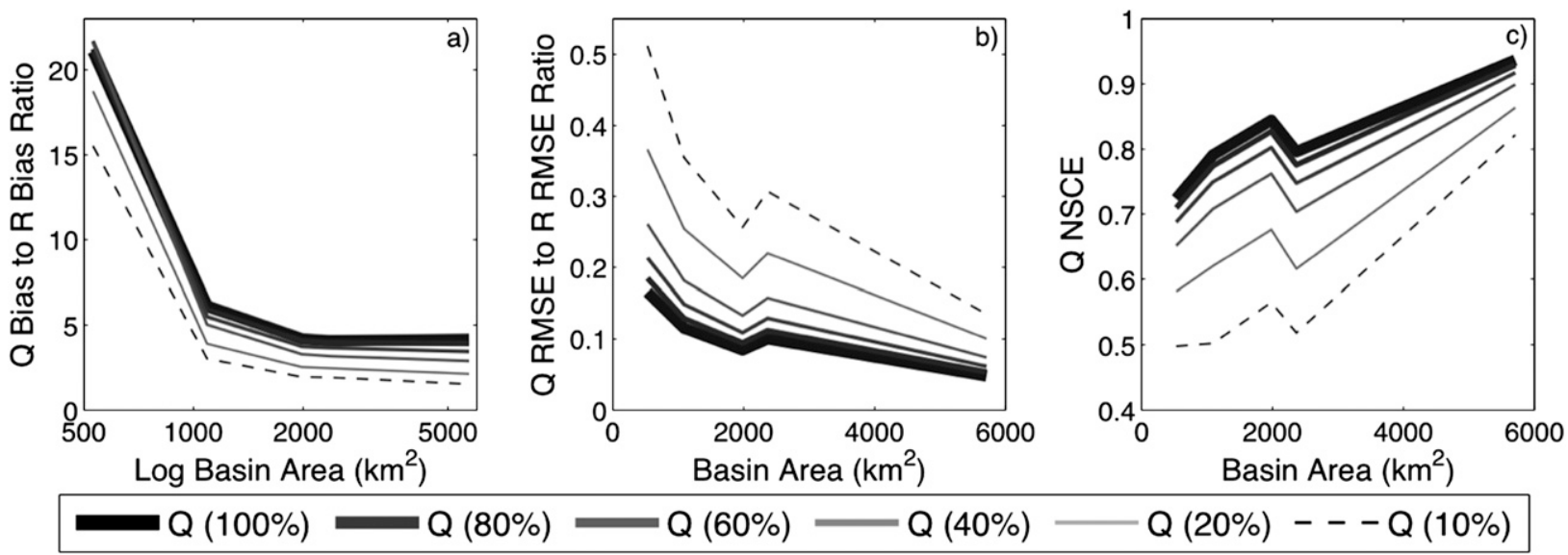

FIG. 6. Overall propagation of mean rainfall error to streamflow simulations. Metrics of model performance as functions of basin area and streamflow threshold are presented: (a) ratio of streamflow $(Q)$ relative bias to rainfall $(R)$ relative bias, (b) ratio of streamflow $(Q)$ relative RMSE to rainfall $(R)$ relative RMSE, and (c) NSCE of streamflow simulations. The values between parentheses indicate the probability of occurrence of the corresponding threshold. 

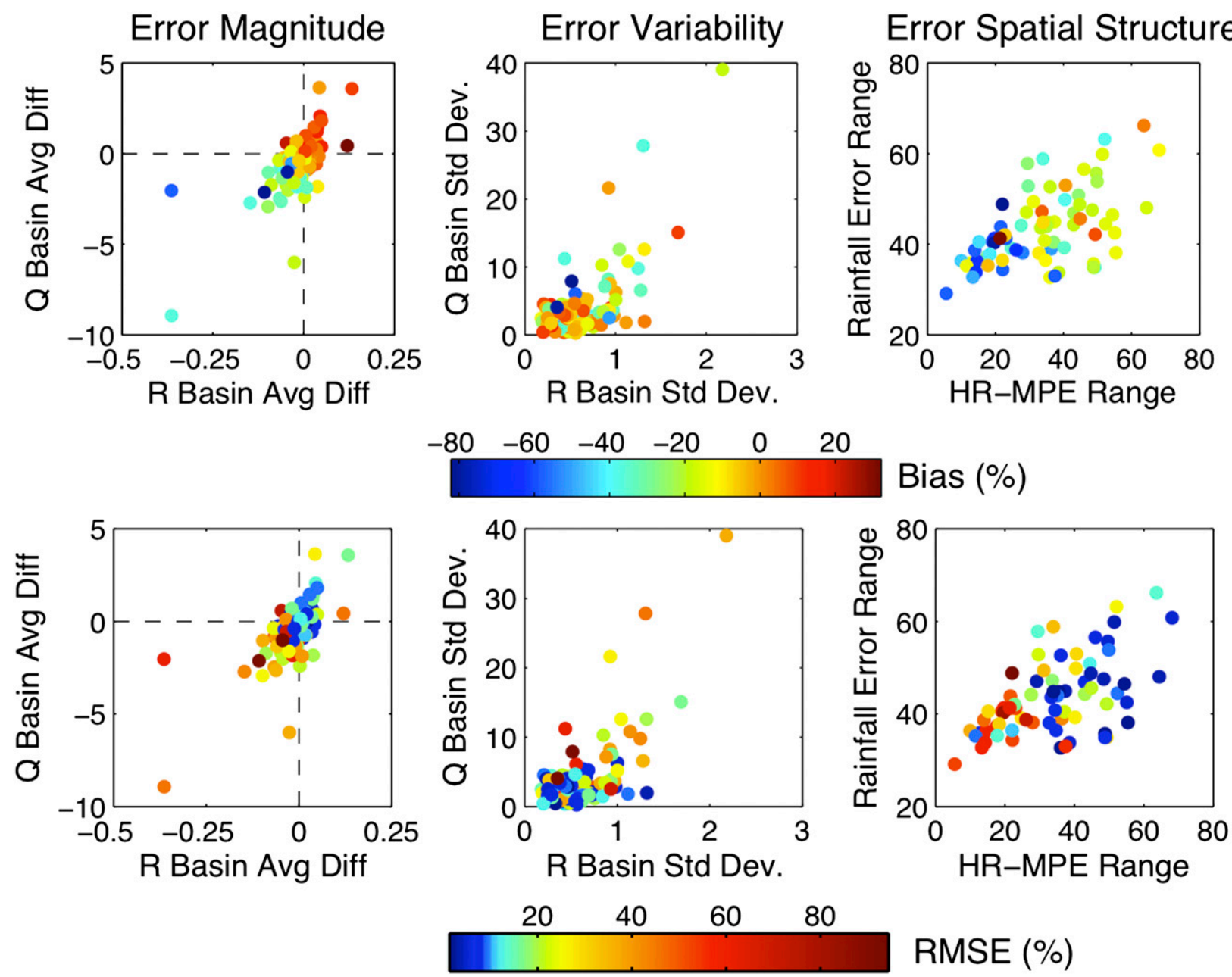

FIG. 7. Summary of error features and their propagation to streamflow modeling at basin outlet for the 100 events. (left) Error magnitude, (middle) error variability, and (right) error spatial structure. The (top) relative bias and (bottom) relative RMSE were computed for streamflow simulations forced by CR-MPE as compared to streamflow simulations forced by HR-MPE at the basin outlet.

either bias or RMSE of streamflow at the basin outlet. Finally, the graphs of error spatial structure (Fig. 7, right) show a linear and direct relationship between the size and/or level of organization of the storms and the spatial correlation structure of the rainfall error, which is consistent with results from section $3 \mathrm{a}$. In terms of the association with error in streamflow simulations at the outlet, there are mainly two aspects that can be observed: 1) even though there is not a very clear trend of the error as depicted by the color gradients, it is possible to distinguish subgroups of events associated with sectors in the error range [i.e., events with RMSE values greater than $\sim 60 \%$ (red-colored points) are grouped toward the lower-left side of the graph, which corresponds to the lower values of variogram's range], which is seen in both the relative bias and the relative RMSE, and 2) events with the highest values of streamflow error, both bias and RMSE, are associated to lower characteristic spatial scale. The first aspect is most probably related to specific conditions of each event that were not accounted for, such as the antecedent soil conditions or the proximity of the storm to the basin outlet. This might also explain why it is not possible to observe a clear relationship between error in the spatial structure of rainfall and error in streamflow at the basin outlet. However, the second aspect indicates that error due to resolution in the estimation of rainfall from small-scale convection will have higher impact on streamflow simulations.

\section{Mitigating input's resolution impacts through model calibration}

\section{a. Evaluation of differences due to rainfall resolution}

A standard procedure when setting up an operational hydrologic model is the calibration of its parameters 
using observations of rainfall and streamflow. This has become a common practice in studies that assess the hydrologic utility of satellite-based QPE, where the hydrologic model is calibrated at the scale corresponding to the algorithm's pixel resolution or to the resolution of a reference rainfall dataset (e.g., from rain gauges). The calibrated parameter set is highly dependent on the characteristics of the QPE used to force the model during the calibration period. Other variables such as the length of period during calibration and the variability of flow conditions and events in the calibration period also play an important role during the adjustment of the parameters. However, the discussion in this section is focused on the differences in model performance caused by QPE resolution. More specifically, the objective is to assess the extent to which model calibration can compensate for errors due to QPE resolution. Other issues in the satellite QPE, such as biases and random errors inherent to the retrieval process, are not explicitly accounted for in the model parameter estimation.

The hydrologic model was calibrated using a generalpurpose optimization algorithm entitled Differential Evolution Adaptive Metropolis (DREAM; Vrugt et al. 2009). DREAM is an adaptation of the widely used University of Arizona shuffled complex evolution algorithm (SCE-UA; Duan et al. 1993). The algorithm employs Markov chain Monte Carlo (MCMC) sampling to estimate the posterior probability density function of parameters using a formal likelihood function, which ensures a collective evolution of the model parameters (i.e., all parameters are optimized simultaneously to account for interdependencies among them). The algorithm is designed to operate in complex, high-dimensional sampling problems (Vrugt et al. 2008). The reader is encouraged to review the work by Vrugt et al. (2009) for more details regarding DREAM. A period of $3 \mathrm{yr}$ (200406) of USGS gauge streamflow observations was used as the reference in the calibration process to compute the sum of squared residuals (SSR; i.e., the objective function). In addition to SSR, a constraint was set in DREAM's algorithm for selecting parameter sets that produced relatively unbiased simulations (i.e., relative bias $<10 \%$ ). The starting point or benchmark of this calibration was the baseline model described in section $3 \mathrm{~b}(1)$. Since the baseline model has spatially distributed parameters estimated from soil and stream observations, the calibration approach was used to generate scaling factors, and thus, the spatial variability dictated by the observations is maintained (i.e., the relative differences among grid cells is preserved). An independent validation period consisting of the data not used for calibration (i.e., 2002-03 and 2007-09) was used to assess the suitability of the resulting parameter sets in terms of relative performance of model skill, conditioned on the different parameter sets. Note that the validation of the method to account for QPE product's resolution is presented in section $4 b$.

To explore the effectiveness of model calibration for mitigating rainfall-resolution errors as a function of spatial scale and to account for scale dependencies in the hydrologic model, each QPE product (i.e., HR-MPE and CR-MPE) was used to automatically calibrate the model parameters at each basin independently; that is, calibration was performed over the entire area associated to each basin (i.e., B1 through B5) ignoring observations at interior locations (e.g., B3 is calibrated over its entire catchment, ignoring the fact that $\mathrm{B} 2$ and B1 exist within it). This array of multiple independent parameter sets is referred to hereafter as "local" calibration, as each parameter set was derived specifically to the basin and to the QPE input. The parameter set that was generated by calibrating the model at the largest scale (i.e., B5) was used to simulate streamflow at interior gauged points to be compared to simulations produced by the local calibration. Therefore, the B5 calibration is referred to hereafter as "regional."

Metrics of overall performance for the resulting calibrated model realizations during both calibration and validation periods are presented in Fig. 8 as a function of basin area. When comparing the results from CR-MPE and HR-MPE in the local calibration runs, we see their skill metrics are very similar, with the only exception in the smallest-scale basin, where differences exist mainly in terms of the direction of bias (i.e., HR-MPE yields a bias of about $10 \%$, while CR-MPE yields a bias of about $-10 \%$ ). Although these similarities in skill (i.e., the closeness of performance metrics across basins) are somewhat reduced during the validation period, particularly for drainage areas under $2000 \mathrm{~km}^{2}$, these results indicate that errors due to QPE resolution can be mitigated or, in other words, accounted for with adjustment of the hydrologic model parameters. Figure 9 presents a comparison of the resulting adjusted parameters after calibration runs forced by HR-MPE and CR-MPE. The values are presented as ratios of CR-MPE-based parameters to HR-MPE-based parameters. These ratios were plotted against basin area to check for correction of basin-scale effects observed in the differences between CR-MPE and HR-MPE in section 3b(2). Some parameters display a clear trend with respect to basin area, which is an indication of the impact of basin-scale and rainfall-resolution difference effects on the calibration results. Such is the case for parameters like UZTWM, UZK, PCTIM, RIVA, ZPERC, LZTWM, LZFPM and LZPK (see Table B1 in appendix B for descriptions). Other parameters do not display any trend, which is an 

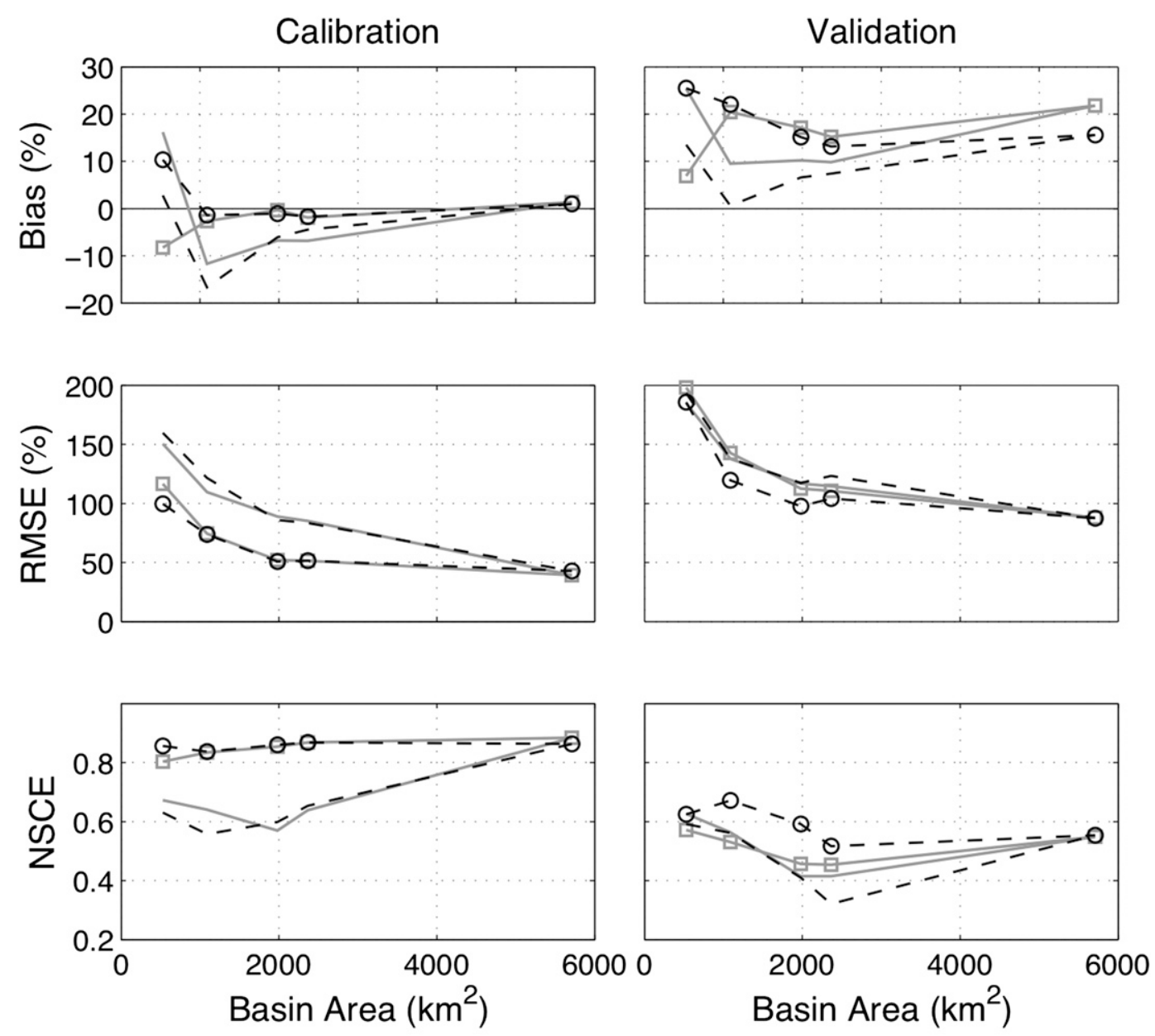

R. HR-MPE

R. CR-MPE

- -๑- - L. HR-MPE

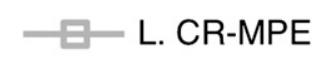

FIG. 8. Summary of (left) calibration and (right) validation results. Metrics of model performance are plotted against basin area for the five subbasins. The " $\mathrm{R}$ " and " $\mathrm{L}$ " refer to regional and local calibration runs, respectively.

indication of low sensitivity to basin-scale effects. Moreover, these random differences in the adjustment of some model parameters between CR-MPE and HR-MPE demonstrate the compensatory effects of model calibration given the random nature of errors introduced by resolution degradation and the stochastic features of the optimization algorithm. The global bias (i.e., the negative bias of CR-MPE streamflow simulations as compared to HR-MPE simulations), on the other hand, was consistently corrected after adjustment of some parameters toward an increase in runoff generation (i.e., the upper-zone depletion rate UZK or the impervious area fraction PCTIM, which directly control runoff generation, and the ratio of percolation rates ZPERC, which controls how much water is lost to the soil). These results might indicate that some parameters could yield reduction of systematic errors when perturbed in a predefined fashion, which would have implications on the issue of parameter transferability to other basins. However, this aspect was not further explored in the present study.

The comparison between local and regional simulations reveals much skill is improved during the calibration period at all basin scales and QPE resolutions using the locally optimized parameter settings (Fig. 8). These local-scale improvements, however, diminish and are essentially indistinguishable from the skill attained with the regional model during the validation period. Note these levels of skill are only achievable by accounting for the QPE-resolution effect in the calibration process. This result has significant implications for forecasting streamflow at ungauged, interior points using a model calibrated with observations at the basin outlet. A natural extension of this result is an analysis of the limiting catchment size for which the regional calibration is effective 

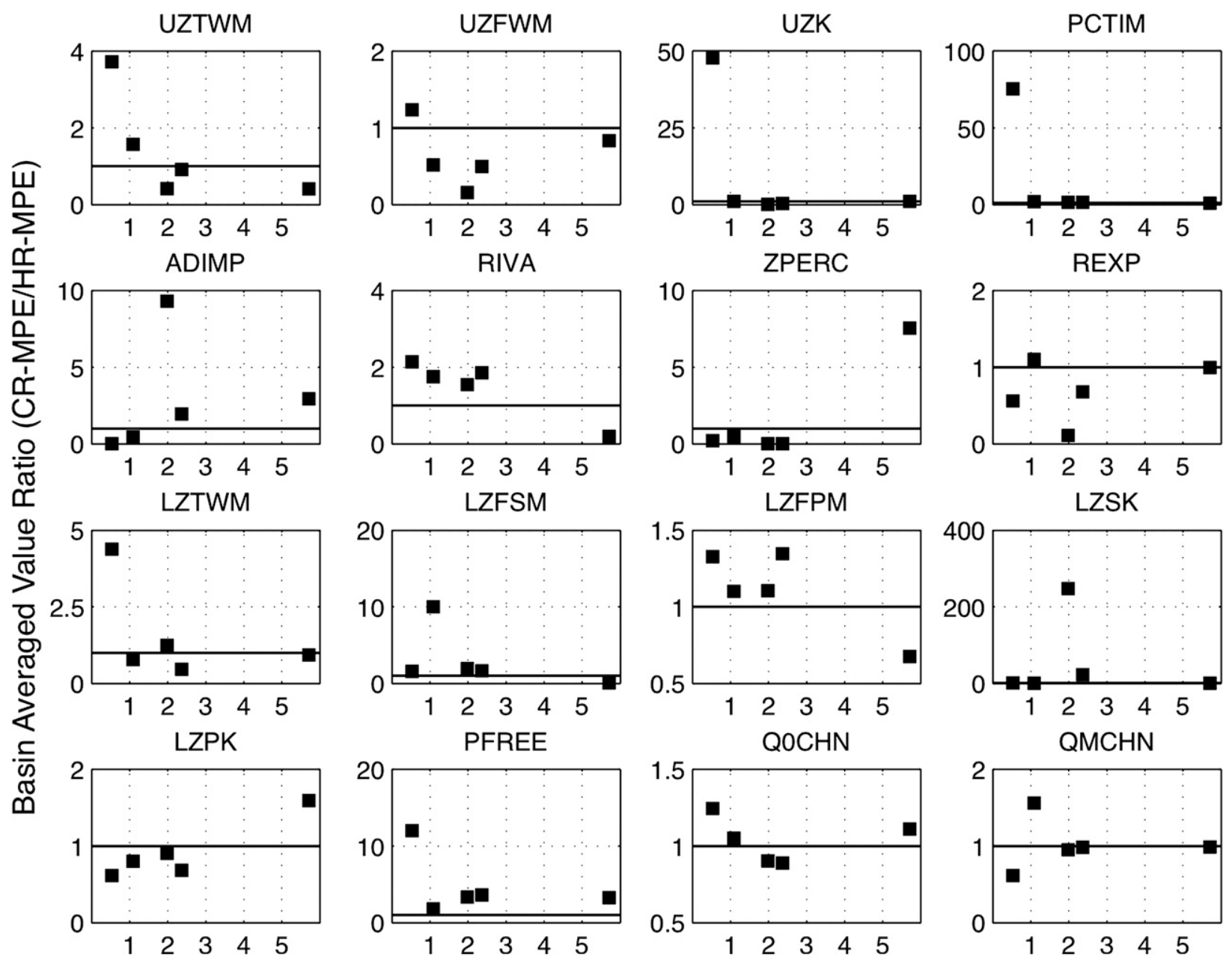

Basin Area $1000\left(\mathrm{~km}^{2}\right)$

FIG. 9. Comparison of adjusted hydrologic model parameters after calibrations forced by HR-MPE and CR-MPE. The graphs present CR-MPE to HR-MPE ratio of parameter basin average values ( $y$ axis) vs basin area ( $x$ axis). The solid horizontal line in each panel indicates where the ratio is 1.0 .

over different regions, which should be investigated in future works.

Last, we notice that the relative RMSE is the only metric that clearly displays the impact of basin scale even during the calibration period, which is most evident for basins under $2000 \mathrm{~km}^{2}$. The impact of basin scale on relative RMSE observed here is consistent with what was observed in the synthetic experiment [section 3b(2)] and previous studies such as the ones by Nijssen and Lettenmaier (2004) and Nikolopoulos et al. (2010), although the latter found a rather counterintuitive behavior: the values of relative RMSE increased with increasing basin size. Nevertheless, these results suggest that the effects of basin scale on aggregated errors might be resistive to model calibration.

\section{b. Validation of method with 3B42RT: Revealing the utility of satellite estimates}

Up to this point, it has been shown that the use of rainfall estimates matching satellite's coarse resolution has a significant impact on the hydrologic modeling of a cascade of basins as compared to the use of a highresolution rainfall product. Furthermore, it has been demonstrated that this impact can be reduced through adjustment of the parameters of the hydrologic model. The last step of this study was to evaluate whether the information gained in the calibration process in terms of input's resolution could be transferred to simulations forced by 3B42RT estimates and more accurately reveal its hydrologic skill. This has important implications in 


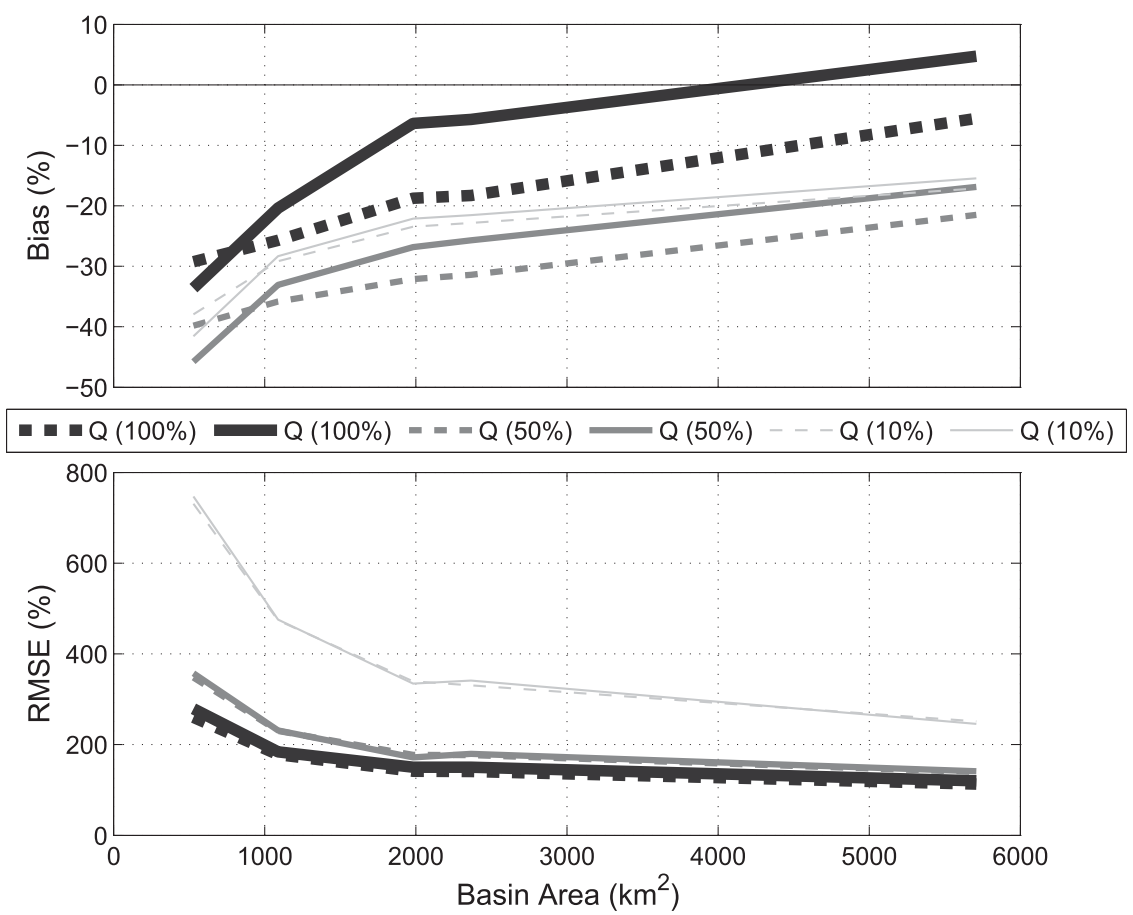

FIG. 10. Relative bias and RMSE of 3B42RT-forced simulations from the two resulting locally calibrated parameter sets over the 2002-09 period. Error metrics are computed using actual streamflow observations from gauged locations. The model using HR-MPE-based parameter set (dashed lines) is compared to the CR-MPE-based parameter set (solid lines) at different streamflow threshold values.

relation to the use of satellite rainfall estimates for hydrologic applications in ungauged basins. Note that the parameter sets resulting from the calibration process in section $4 \mathrm{a}$ are assumed to be representative of the true and best characterization of basin physical properties and processes. Therefore, the resulting model configuration may be used for an evaluation of alternative input data such as satellite rainfall products.

Streamflow simulations for the period of data (i.e., 2002-09) were thus generated, forcing the hydrologic model with 3B42RT using both locally optimized sets of parameters (i.e., local CR-MPE and HR-MPE associated parameter sets). Figure 10 presents metrics of skill for the overall performance of both models at the selected basin scales and for different streamflow thresholds. In terms of relative RMSE, there are little differences between the simulations, which might indicate that aggregated errors from other sources of uncertainty in the generation of the 3B42RT product overshadow the resolution effect. In terms of relative bias, however, it can be seen that the model calibrated with CR-MPE performed better than the model calibrated with HRMPE, although the differences reduce with decreasing basin scale and streamflow probability of occurrence. In terms of the general performance of 3B42RT, the significant negative bias, which increases toward the headwater basin, is consistent with the gradient of rainfall bias observed in Fig. 2c. These results clearly indicate that accounting for satellite-based QPE's resolution in an explicit manner can help in the evaluation of 3B42RT's hydrologic utility.

This overall improvement in bias on the simulations forced by 3B42RT relates back to the compensation from the adjustment of parameters analyzed in section 4a. These results support the idea that model calibration can be used to account for inputs' resolution. The basis of the approach lies in the fact that it is possible to force model calibration to place emphasis on a desired correction. We have purposely introduced "extra" error in the input data (i.e., HR-MPE) by altering its resolution (i.e., CR-MPE), which results in adjustments of model parameters to reduce the overall error in the hydrologic simulations, including that from the resolution degradation. This method can be used to establish a benchmark model for the evaluation of satellite rainfall products. Establishing the hydrologic utility of GPM-era QPE products, whose spatial resolution is anticipated to be upgraded to $0.1^{\circ}(\sim 10 \mathrm{~km}$; Smith et al. 2007 ; Huffman et al. 2012), will be a subject of many future studies. The results from this work should, therefore, be considered 


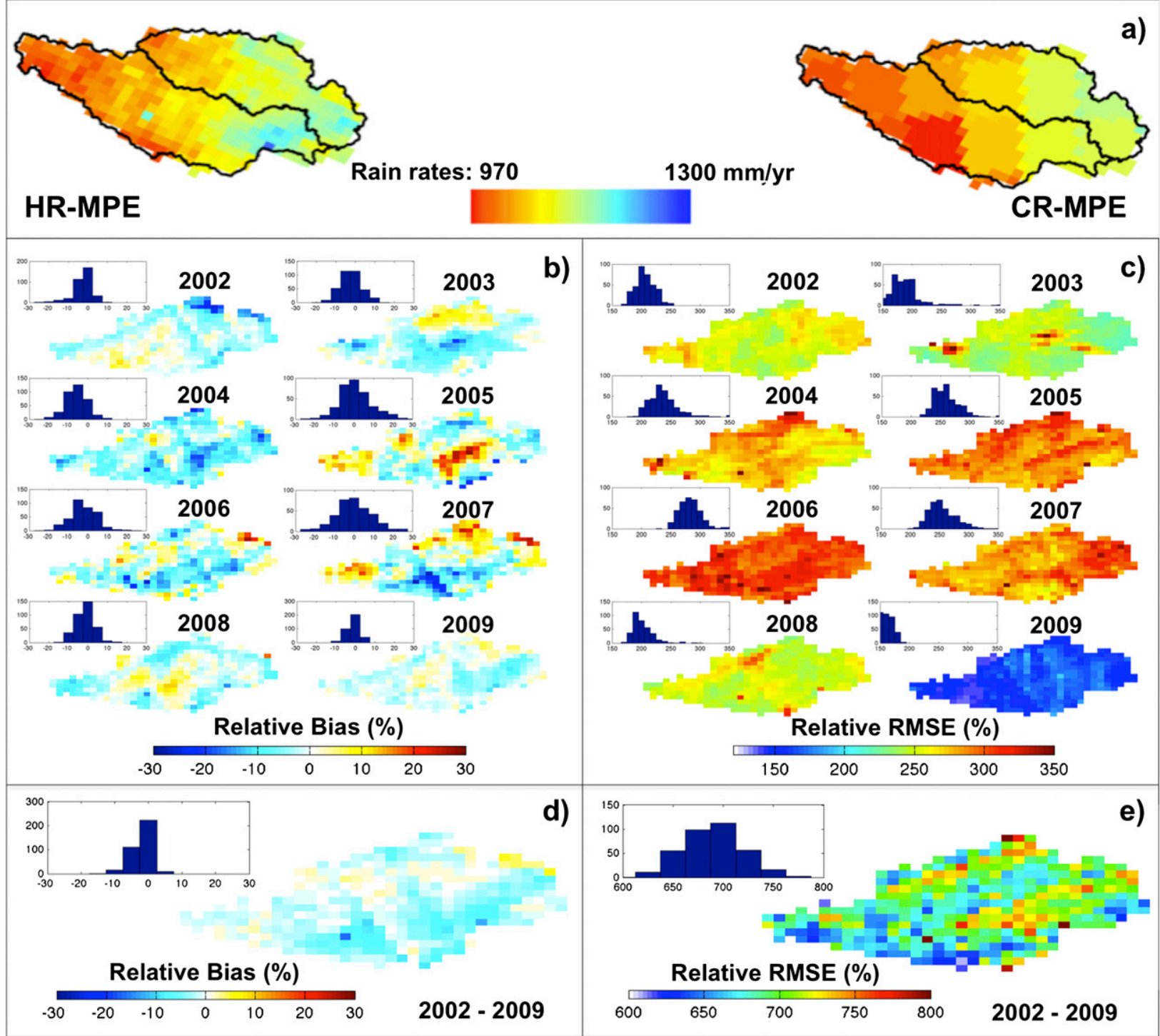

FIG. A1. Comparison of rain fields between HR-MPE and CR-MPE for the study area from 2002 to 2009: (a) mean annual rainfall over the study area for HR-MPE and CR-MPE, (b) relative bias (\%) for each year, (c) relative RMSE (\%) for each year, (d) relative bias for the whole period, and (e) relative RMSE for the whole period. Histograms summarizing the spatial variability of the errors are presented for each panel. Computations are based on hourly rainfall estimates.

in the design of such studies. Additionally, accounting for input's resolution in the model calibration process helps to prevent the necessity of recalibration every time an upgrade on the algorithm for QPE generation is done (e.g., to date, the 3B42 algorithm has been upgraded seven times).

\section{Summary and conclusions}

This work was designed to explore the effects that resolution of QPE has on hydrologic simulations in the context of current and next generation satellite-based
QPE products. The study focused on the Tar River basin in coastal North Carolina, where a cascade of five catchments with drainage areas ranging from 529 to $5709 \mathrm{~km}^{2}$ were used to assess the scale dependence, regionalization of parameter sets, and effect of QPE resolution on hydrologic simulations. A high-quality, high-resolution QPE product, used operationally in the U.S. National Weather Service, was employed as the rainfall reference product. The reference QPE product called MPE $(4 \mathrm{~km} / 1 \mathrm{~h})$ was resampled to current satellite-based QPE resolution in space and time $(25 \mathrm{~km} / 3 \mathrm{~h})$. Differences in rainfall estimates between the high-resolution MPE (HR-MPE) 
B1
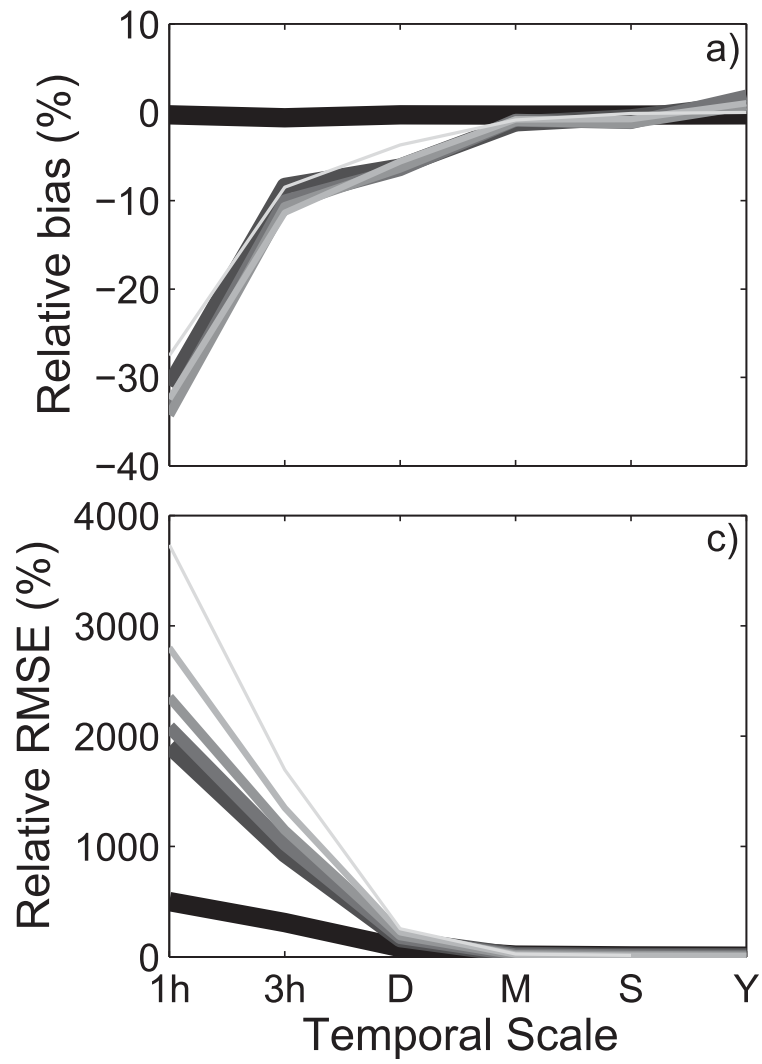

B5
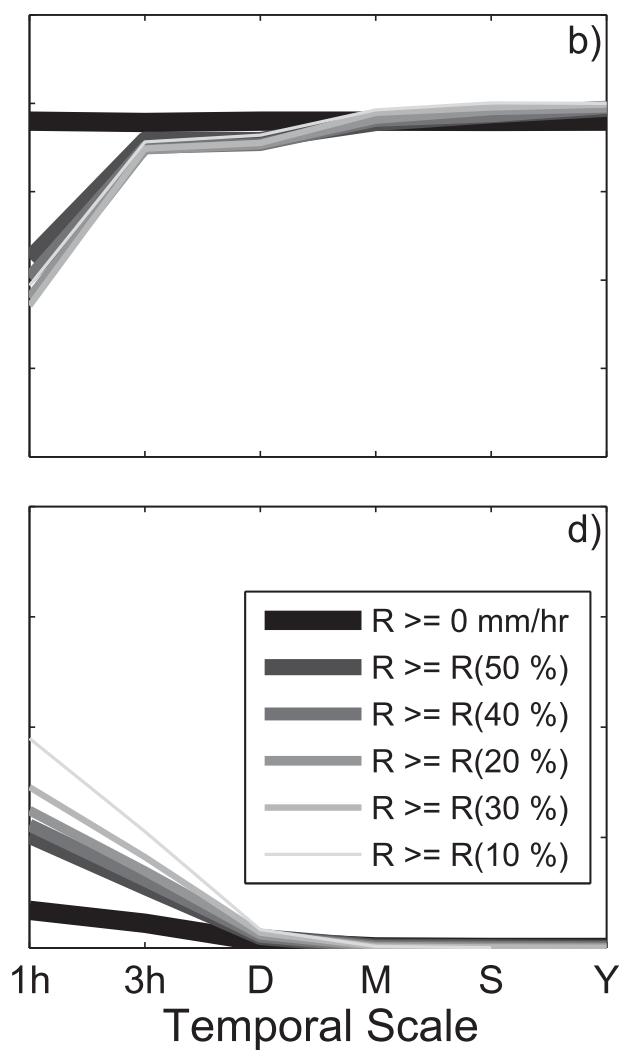

FIG. A2. Error evaluation of basin-averaged rainfall time series as a function of rainfall threshold at different temporal scales (D, daily; M, monthly; S, seasonal; Y, annual): (a) relative bias for basin B1, (b) relative bias for basin B5, (c) relative RMSE for basin B1, and (d) relative RMSE for basin B5. The 1-h scale refers to instantaneous rain rates (disaggregated from $3 \mathrm{~h}$ ), while the remaining scales refer to values aggregated from 3-h rain rates. The values in parentheses in the legend indicate the frequency associated to the threshold rainfall value (i.e., percentage of time a given value occurred) based on nonzero data points.

and the coarse-resolution MPE (CR-MPE) were evaluated considering different error features, including spatial structure and variability through an analysis of 100 events. A sensitivity analysis with a synthetic experiment using the uncalibrated model was then performed to effectively isolate the QPE resolution effect on hydrologic simulations. Finally, the hydrologic model was calibrated using measurements from the gauged sites for the two QPE resolutions (i.e., CR-MPE and HRMPE). The resulting calibrated models were then forced with TRMM's 3B42RT rainfall estimates. Conclusions derived from this work are summarized as follows.

Degradation of QPE resolution has a clear impact on rainfall fields in terms of global bias and aggregated errors. Moreover, it was observed that resolution degradation alters the spatial structure of rainfall, introducing considerable amounts of aggregated error. This alteration and its resulting error are directly proportional to the characteristic spatial structure and scale of each storm event.
The sensitivity analysis on the overall impacts of resolution degradation on hydrologic simulations shows that the global bias of rainfall is magnified while the aggregated errors are dampened. These error propagation behaviors are correlated with the size of the basin. The magnification of the bias increases with decreasing basin area, reaching magnification factors of about 20 . The dampening of aggregated errors increases with increasing basin size, also reaching dampening factors of about 20. Furthermore, the dampening effect of aggregated errors significantly decreases with increasing streamflow values, while the magnification of bias is not significantly affected.

The analysis on the three error features of rainfall (namely, magnitude, spatial variability, and spatial structure) indicates that errors in streamflow are mostly related to the effects that resolution has on the magnitude of rainfall. Even though the spatial variability of rainfall error is well correlated with the spatial variability 
TABLE B1. Description of SAC-SMA model parameters.

\begin{tabular}{|c|c|c|}
\hline & Parameter & Description \\
\hline \multirow[t]{11}{*}{ Spatially distributed } & UZTWM & The upper-layer tension water capacity (mm) \\
\hline & UZFWM & The upper-layer free water capacity (mm) \\
\hline & UZK & Interflow depletion rate from the upper layer free water storage $\left(\right.$ day $\left.^{-1}\right)$ \\
\hline & ZPERC & Ratio of maximum and minimum percolation rates \\
\hline & REXP & Shape parameter of the percolation curve \\
\hline & LZTWM & The lower-layer tension water capacity $(\mathrm{mm})$ \\
\hline & LZFSM & The lower-layer supplemental free water capacity $(\mathrm{mm})$ \\
\hline & LZFPM & The lower-layer primary free water capacity $(\mathrm{mm})$ \\
\hline & LZSK & Depletion rate of the lower-layer supplemental free water storage $\left(\mathrm{day}^{-1}\right)$ \\
\hline & LZPK & Depletion rate of the lower-layer primary free water storage $\left(\right.$ day $\left.^{-1}\right)$ \\
\hline & PFREE & Percolation fraction that goes directly to the lower-layer free water storages \\
\hline \multirow[t]{6}{*}{ Lumped } & PCTIM & Permanent impervious area fraction \\
\hline & ADIMP & Maximum fraction of an additional impervious area due to saturation \\
\hline & RIVA & Riparian vegetation area fraction \\
\hline & SIDE & Ratio of deep percolation from lower-layer free water storages \\
\hline & RSERV & Fraction of lower-layer free water not transferable to lower-layer tension water \\
\hline & EFC & Effective forest fraction \\
\hline
\end{tabular}

of streamflow error, the hydrologic filtering effect of the basin obscures its impact on the errors at integration locations (i.e., basin outlets). Similarly, the effect on the spatial structure of rainfall could not be well established for the same reason and because specific conditions of each event were not accounted for. However, this analysis indicated that events of significant streamflow error were associated to error in the spatial structure of rainfall from small-scale convection.

The results from the calibration procedure clearly demonstrate that adjustment of model parameters can be used as a mean to account for the effects of input's resolution over hydrologic simulations. The validation with 3B42RT demonstrated that significant reduction in relative bias is attained when using the parameter set that accounted for input's resolution.

Overall, these results illustrate the importance of resolution and its close relation with scale for satellitebased applications, particularly when determining the hydrologic utility of satellite rainfall. Accounting for rainfall's resolution effect is essential when evaluating satellite rainfall algorithms using a hydrologic model. Likewise, this work indicates the significant improvements that could potentially be expected from the next generation satellite rainfall products associated with GPM, considering the anticipated upgrade in resolution and improvements in retrieval capabilities. Results from this study indicate improvements due to resolution are most needed in the smallest-scale basins for highmagnitude events, such as flash floods. Furthermore, the analysis on calibration results suggests that model calibration needs to consider scale. Future studies need to explore the issue on the persistent impact of basin scale on aggregated errors. Likewise, it would be helpful to extend some of the analysis performed herein to different regions and to a wider range of basin sizes to improve our understanding on issues such as 1) the transferability of information from basin outlet to interior locations, 2) the transferability of systematic perturbations of particular model parameters to account for input resolution, and 3) the characterization of the impact of resolution degradation on particular storm types.

\section{APPENDIX A}

\section{Error Evaluation of Rainfall Estimates after Resolution Degradation}

See Figs. A1 and A2.

\section{APPENDIX B}

\section{List and Description of SAC-SMA Model Parameters}

See Table B1.

\section{REFERENCES}

Arnaud, P., C. Bouvier, L. Cisneros, and R. Dominguez, 2002: Influence of rainfall spatial variability on flood prediction. J. Hydrol., 260, 216-230, doi:10.1016/S0022-1694(01)00611-4.

Artan, G., H. Gadain, J. L. Smith, K. Asante, C. J. Bandaragoda, and J. P. Verdin, 2007: Adequacy of satellite derived rainfall data for stream flow modeling. Nat. Hazards, 43, 167-185, doi:10.1007/s11069-007-9121-6.

Berne, A., G. Delrieu, J.-D. Creutin, and C. Obled, 2004: Temporal and spatial resolution of rainfall measurements required for urban hydrology. J. Hydrol., 299, 166-179. 
Boyle, D. P., H. V. Gupta, and S. Sorooshian, 2000: Toward improved calibration of hydrologic models: Combining the strengths of manual and automatic methods. Water Resour. Res., 36, 3663-3674, doi:10.1029/2000WR900207.

Briedenbach, J. P., and J. S. Bradberry, 2001: Multisensor precipitation estimates produced by the National Weather Service River Forecast Centers for hydrologic applications. Proc. 2001 Georgia Water Resources Conf., Athens, GA, Institute of Ecology, University of Georgia, 179-182.

Burnash, R. J. C., R. L. Ferral, and R. A. McGuire, 1973: A general streamflow simulation system-Conceptual modeling for digital computers. Tech. Rep. to the Joint Federal and State River Forecast Center, U.S. National Weather Service and California Department of Water Resources, Sacramento, CA, 204 pp.

Dinku, T., E. N. Anagnostou, and M. Borga, 2002: Improving radarbased estimation of rainfall over complex terrain. J. Appl. Meteor., 41, 1163-1178, doi:10.1175/1520-0450(2002)041<1163: IRBEOR $>2.0 . \mathrm{CO} ; 2$.

— , F. Ruiz, S. J. Connor, and P. Ceccato, 2010: Validation and intercomparison of satellite rainfall estimates over Colombia. J. Appl. Meteor. Climatol., 49, 1004-1014, doi:10.1175/ 2009JAMC2260.1.

Duan, Q., V. K. Gupta, and S. Sorooshian, 1993: Shuffled complex evolution approach for effective and efficient global minimization. J. Optim. Theory Appl., 76, 501-521, doi:10.1007/ BF00939380.

Faurès, J. M., D. Goodrich, D. A. Woolhiser, and S. Sorooshian, 1995: Impact of small-scale spatial rainfall variability on runoff modeling. J. Hydrol., 173, 309-326, doi:10.1016/ 0022-1694(95)02704-S.

Fulton, R., 2002: Activities to improve WSR-88D Radar Rainfall Estimation in the National Weather Service. Proc. Second Federal Interagency Hydrologic Modeling Conf., Las Vegas, NV, USGS, 11 pp. [Available online at http://www.nws.noaa. gov/oh/hrl/papers/wsr88d/qpe_hydromodelconf_web.pdf.]

Gourley, J. J., Y. Hong, Z. L. Flamig, L. Li, and J. Wang, 2010: Intercomparison of rainfall estimates from radar, satellite, gauge, and combinations for a season of record rainfall. J. Appl. Meteor. Climatol., 49, 437-452, doi:10.1175/2009JAMC2302.1.

,,,--- J. Wang, H. Vergara, and E. N. Anagnostou, 2011: Hydrologic evaluation of rainfall estimates from radar, satellite, gauge, and combinations on Ft. Cobb Basin, Oklahoma. J. Hydrometeor., 12, 973-988, doi:10.1175/2011JHM1287.1.

Hong, Y., K.-L. Hsu, H. Moradkhani, and S. Sorooshian, 2006: Uncertainty quantification of satellite precipitation estimation and Monte Carlo assessment of the error propagation into hydrologic response. Water Resour. Res., 42, W08421, doi:10.1029/ 2005WR004398.

—, R. F. Adler, F. Hossain, S. Curtis, and G. J. Huffman, 2007: A first approach to global runoff simulation using satellite rainfall estimation. Water Resour. Res., 43, W08502, doi:10.1029/ 2006WR005739.

Hossain, F., and E. N. Anagnostou, 2004: Assessment of current passive-microwave- and infrared-based satellite rainfall remote sensing for flood prediction. J. Geophys. Res., 109, D07102, doi:10.1029/2003JD003986.

_ rainfall error model for ensemble generation of satellite rainfall data. IEEE Geosci. Remote Sens. Lett., 3, 419-423, doi:10.1109/ LGRS.2006.873686.

$\longrightarrow$, and - 2006b: A two-dimensional satellite rainfall error model. IEEE Trans. Geosci. Remote Sens., 44, 1511-1522, doi:10.1109/TGRS.2005.863866.
— , and D. P. Lettenmaier, 2006: Flood prediction in the future: Recognizing hydrologic issues in anticipation of the Global Precipitation Measurement mission. Water Resour. Res., 42, W11301, doi:10.1029/2006WR005202.

, and G. J. Huffman, 2008: Investigating error metrics for satellite rainfall data at hydrologically relevant scales. J. Hydrometeor., 9, 563-575, doi:10.1175/2007JHM925.1.

_ and N. Katiyar, 2008: Advancing the use of satellite rainfall datasets for flood prediction in ungauged basins: The role of scale, hydrologic process controls and the Global Precipitation Measurement mission. Quantitative Information Fusion for Hydrological Sciences, Springer, 163-181.

Huffman, G. J., and Coauthors, 2007: The TRMM multisatellite precipitation analysis (TMPA): Quasi-global, multiyear, combinedsensor precipitation estimates at fine scales. J. Hydrometeor., 8, 3855, doi:10.1175/JHM560.1.

— D. T. Bolvin, D. Braithwaite, K. Hsu, R. Joyce, and P. Xie, 2012: NASA Global Precipitation Measurement (GPM) Integrated Multi-Satellite Retrievals for GPM (IMERG). Algorithm Theoretical Basis Doc. Version 3, National Aeronautics and Space Administration, 25 pp. [Available online at http:// pmm.nasa.gov/sites/default/files/document_files/IMERG_ ATBD_V3.0.doc.]

Journel, A. G., and C. J. Huijbregts, 1978: Mining Geostatistics. Academic Press, 600 pp.

Kidd, C., D. R. Kniveton, M. C. Todd, and T. J. Bellerby, 2003: Satellite rainfall estimation using combined passive microwave and infrared algorithms. J. Hydrometeor., 4, 1088-1104, doi:10.1175/1525-7541(2003)004<1088:SREUCP >2.0.CO;2.

Kirstetter, P.-E., G. Delrieu, B. Boudevillain, and C. Obled, 2010: Toward an error model for radar quantitative precipitation estimation in the Cévennes-Vivarais region, France. J. Hydrol., 394, 28-41, doi:10.1016/j.jhydrol.2010.01.009.

— error modeling of spaceborne precipitation radar with NOAA/ NSSL ground radar-based National Mosaic QPE. J. Hydrometeor., 13, 1285-1300, doi:10.1175/JHM-D-11-0139.1.

Koren, V., B. Finnerty, J. Schaake, M. Smith, D. J. Seo, and Q. Y. Duan, 1999: Scale dependencies of hydrologic models to spatial variability of precipitation. J. Hydrol., 217, 285-302, doi:10.1016/S0022-1694(98)00231-5.

—, M. Smith, D. Wang, and Z. Zhang, 2000: Use of soil property data in the derivation of conceptual rainfall-runoff model parameters. Proc. 15th Conf. on Hydrology, Long Beach, CA, Amer. Meteor. Soc., 103-106. [Available online at https://ams. confex.com/ams/annual2000/webprogram/Paper6074.html.]

, - - Q. Duan, Q. Duan, H. Gupta, S. Sorooshian, A. Rousseau, and R. Turcotte, 2003. Use of a priori parameter estimates in the derivation of 9 spatially consistent parameter sets of rainfall-runoff models. Calibration of Watershed Models, Q. Duan et al., Eds., Water Science and Application Series, Vol. 6, Amer. Geophys. Union, 239-254.

, S. Reed, M. Smith, Z. Zhang, and D. J. Seo, 2004: Hydrology laboratory research modeling system (HL-RMS) of the US national weather service. J. Hydrol., 291, 297-318, doi:10.1016/ j.jhydrol.2003.12.039.

Kouwen, N., and G. Garland, 1989: Resolution considerations in using radar rainfall data for flood forecasting. Can. J. Civ. Eng., 16, 279-289, doi:10.1139/189-053.

Krajewski, W. F., V. Lakshmi, K. P. Georgakakos, and S. C. Jain, 1991: A Monte Carlo study of rainfall sampling effect on a distributed catchment model. Water Resour. Res., 27, 119128, doi:10.1029/90WR01977. 
Lebel, T., G. Bastin, C. Obled, and J. Creutin, 1987: On the accuracy of areal rainfall estimation: A case study. Water Resour. Res., 23, 2123-2134, doi:10.1029/WR023i011p02123.

Li, L., and Coauthors, 2009: Evaluation of the real-time TRMMbased multi-satellite precipitation analysis for an operational flood prediction system in Nzoia basin, Lake Victoria, Africa. Nat. Hazards, 50, 109-123, doi:10.1007/s11069-008-9324-5.

Maggioni, V., R. H. Reichle, and E. N. Anagnostou, 2011: The effect of satellite rainfall error modeling on soil moisture prediction uncertainty. J. Hydrometeor., 12, 413-428, doi:10.1175/ 2011JHM1355.1.

McCollum, J. R., W. F. Krajewski, R. R. Ferraro, and M. B. Ba, 2002: Evaluation of biases of satellite rainfall estimation algorithms over the continental United States. J. Appl. Meteor., 41, 1065-1080, doi:10.1175/1520-0450(2002)041<1065:EOBOSR > 2.0.CO;2.

Mohamoud, Y. M., and L. M. Prieto, 2012: Effect of temporal and spatial rainfall resolution on HSPF predictive performance and parameter estimation. J. Hydrol. Eng., 17, 377-388, doi:10.1061/(ASCE)HE.1943-5584.0000457.

Nijssen, B., and D. P. Lettenmaier, 2004: Effect of precipitation sampling error on simulated hydrological fluxes and states: Anticipating the Global Precipitation Measurement satellites. J. Geophys. Res., 109, D02103, doi:10.1029/2003JD003497.

Nikolopoulos, E. I., E. N. Anagnostou, F. Hossain, M. Gebremichael, and M. Borga, 2010: Understanding the scale relationships of uncertainty propagation of satellite rainfall through a distributed hydrologic model. J. Hydrometeor., 11, 520-532, doi:10.1175/ 2009JHM1169.1.

NWS, 2008: Hydrology Laboratory-Research Distributed Hydrologic Model (HL-RDHM) User Manual V. 2.4.2. National Weather Service, $108 \mathrm{pp}$. [Available online at http://www. cbrfc.noaa.gov/present/rdhm/RDHM_User_Manual.pdf.]

Obled, C., J. Wendling, and K. Beven, 1994: The sensitivity of hydrological models to spatial rainfall patterns: An evaluation using observed data. J. Hydrol., 159, 305-333, doi:10.1016/ 0022-1694(94)90263-1.

Ogden, F. L., and P. Y. Julien, 1993: Runoff sensitivity to temporal and spatial rainfall variability at runoff plane and small basin scales. Water Resour. Res., 29, 2589-2598, doi:10.1029/ 93WR00924.

— fall resolution. J. Hydrol., 158, 1-18, doi:10.1016/ 0022-1694(94)90043-4.

Pereira Filho, A. J., R. E. Carbone, J. E. Janowiak, P. Arkin, R. Joyce, R. Hallak, and C. G. Ramos, 2010: Satellite rainfall estimates over South America-Possible applicability to the water management of large watersheds. J. Amer. Water Resour. Assoc., 46, 344-360, doi:10.1111/j.1752-1688.2009.00406.x.

Pokhrel, P., H. Gupta, and T. Wagener, 2008: A spatial regularization approach to parameter estimation for a distributed watershed model. Water Resour. Res., 44, W12419, doi:10.1029/ 2007WR006615.

Sapiano, M., and P. Arkin, 2009: An intercomparison and validation of high-resolution satellite precipitation estimates with 3hourly gauge data. J. Hydrometeor., 10, 149-166, doi:10.1175/ 2008JHM1052.1.

Schaake, J., 1989: Importance of the HRAP grid for operational hydrology. Preprints, United States/People's Republic of China Flood Forecasting Symp., Portland, OR, NOAA/NWS, 331355.

Scheel, M. L. M., M. Rohrer, C. Huggel, D. Santos Villar, E. Silvestre, and G. J. Huffman, 2011: Evaluation of TRMM Multi-satellite Precipitation Analysis (TMPA) performance in the central Andes region and its dependency on spatial and temporal resolution. Hydrol. Earth Syst. Sci., 15, 2649-2663, doi:10.5194/hess-15-2649-2011.

Segond, M. L., H. S. Wheater, and C. Onof, 2007: The significance of spatial rainfall representation for flood runoff estimation: A numerical evaluation based on the Lee catchment, UK. J. Hydrol., 347, 116-131, doi:10.1016/j.jhydrol.2007.09.040.

Seo, D.-J., A. Seed, and G. Delrieu, 2010. Radar and multisensor rainfall estimation for hydrologic applications. Rainfall: State of the Science, Geophys. Monogr., Vol. 191, Amer. Geophys. Union, 79-104.

Smith, E., and Coauthors, 2007: International global precipitation measurement (GPM) program and mission: An overview. Measuring Precipitation from Space, V. Levizzani, P. Bauer, and F. J. Turk, Eds., Advances in Global Change Research, Vol. 28, Springer, 611-653.

Smith, M. B., V. I. Koren, Z. Zhang, S. M. Reed, J. J. Pan, and F. Moreda, 2004: Runoff response to spatial variability in precipitation: An analysis of observed data. J. Hydrol., 298, 267-286, doi:10.1016/j.jhydrol.2004.03.039.

Soil Survey Staff, 1994: State Soil Geographic (STATSGO) Data Base: Data use information. Miscellaneous Publ. 1492, National Soil Survey Center, Soil Conservation Service, U.S. Department of Agriculture, 113 pp. [Available online at http:// dbwww.essc.psu.edu/dbtop/doc/statsgo/statsgo_db.pdf.]

__ 1996: Soil Survey Laboratory methods manual. Soil Survey Investigations Rep. 42, version 3.0, National Soil Survey Center, Soil Conservation Service, U.S. Department of Agriculture, $693 \mathrm{pp}$. [Available online at ftp://ftp-fc.sc.egov.usda. gov/NSSC/Lab_Methods_Manual/ssir42.pdf.]

Sorooshian, S., Q. Duan, and V. K. Gupta, 1993: Calibration of rainfall-runoff models: Application of global optimization to the Sacramento Soil Moisture Accounting Model. Water Resour. Res., 29, 1185-1194, doi:10.1029/92WR02617.

Su, F., Y. Hong, and D. P. Lettenmaier, 2008: Evaluation of TRMM Multisatellite Precipitation Analysis (TMPA) and its utility in hydrologic prediction in the La Plata Basin. J. Hydrometeor., 9, 622-640, doi:10.1175/2007JHM944.1.

Syed, K. H., D. C. Goodrich, D. E. Myers, and S. Sorooshian, 2003: Spatial characteristics of thunderstorm rainfall fields and their relation to runoff. J. Hydrol., 271, 1-21, doi:10.1016/S00221694(02)00311-6.

USGS, cited 2011: Instantaneous Data Archive. [Available online at http://ida.water.usgs.gov/ida/.]

Van Cooten, S., and Coauthors, 2011: The CI-FLOW Project: A system for total water level prediction from the summit to the sea. Bull. Amer. Meteor. Soc., 92, 1427-1442, doi:10.1175/ 2011BAMS3150.1.

Vrugt, J. A., C. J. F. ter Braak, H. V. Gupta, and B. A. Robinson, 2008: Equifinality of formal (DREAM) and informal (GLUE) Bayesian approaches in hydrologic modeling? Stochastic Environ. Res. Risk Assess., 23, 1011-1026.

C. G. H. Diks, B. A. Robinson, J. M. Hyman, and D. Higdon, 2009: Accelerating Markov chain Monte Carlo simulation by differential evolution with self-adaptive randomized subspace sampling. Int. J. Nonlinear Sci. Numer. Simul., 10, 273-290, doi:10.1515/IJNSNS.2009.10.3.273.

Wang, Y. I., B. I. N. He, and K. Takase, 2009: Effects of temporal resolution on hydrological model parameters and its impact on prediction of river discharge/Effets de la résolution temporelle sur les paramètres d'un modèle hydrologique et impact sur la prévision de l'écoulement en rivière. Hydrol. Sci. J., 54, 886-898, doi:10.1623/hysj.54.5.886. 
Yilmaz, K. K., T. S. Hogue, K.-1. Hsu, S. Sorooshian, H. V. Gupta, and T. Wagener, 2005: Intercomparison of rain gauge, radar, and satellite-based precipitation estimates with emphasis on hydrologic forecasting. J. Hydrometeor., 6, 497-517, doi:10.1175/ JHM431.1.

- H. V. Gupta, and T. Wagener, 2008: A process-based diagnostic approach to model evaluation: Application to the NWS distributed hydrologic model. Water Resour. Res., 44, W09417, doi:10.1029/2007WR006716.
Yong, B., L. L. Ren, Y. Hong, J. H. Wang, J. J. Gourley, S. H. Jiang, X. Chen, and W. Wang, 2010: Hydrologic evaluation of Multisatellite Precipitation Analysis standard precipitation products in basins beyond its inclined latitude band: A case study in Laohahe basin, China. Water Resour. Res., 46, W07542, doi:10.1029/2009WR008965.

Younger, P. M., J. E. Freer, and K. J. Beven, 2009: Detecting the effects of spatial variability of rainfall on hydrological modelling within an uncertainty analysis framework. Hydrol. Processes, 23, 1988-2003, doi:10.1002/hyp.7341. 